\title{
Article
}

\section{Design and Control of Heat-Integrated Reactors}

\author{
Yih-Hang Chen, and Cheng-Ching Yu
}

Ind. Eng. Chem. Res., 2003, 42 (12), 2791-2808 • DOI: 10.1021/ie020324r

Downloaded from http://pubs.acs.org on November 28, 2008

\section{More About This Article}

Additional resources and features associated with this article are available within the HTML version:

- $\quad$ Supporting Information

- Access to high resolution figures

- Links to articles and content related to this article

- Copyright permission to reproduce figures and/or text from this article

\section{View the Full Text HTML}

\section{ACS Publications}




\title{
PROCESS DESIGN AND CONTROL
}

\section{Design and Control of Heat-Integrated Reactors}

\author{
Yih-Hang Chen ${ }^{\dagger}$ and Cheng-Ching Yu, $\mathbf{u}^{*, \neq}$ \\ Department of Chemical Enginering, National Taiwan University of Science and Technology, \\ Taipe 106-07, Taiwan, and Department of Chemical Engineering, National Taiwan University, \\ Taipe 106-17, Taiwan
}

\begin{abstract}
The objective of this work is to quantify the controllability of a complex heat-integrated reactor. Similarly to the concept of ultimate gain in the control literature, the ultimate effectiveness is defined for a complex feed-effluent heat exchanger (FEHE) scheme. This parameter indicates the amount of heat that can be recovered (via FEHE) before the overall open-loop system becomes unstable. First, a systematic approach is proposed to model the complex heat-integrated reactors. A simple measure, the overall effectiveness, can be derived directly from the flowsheet. Given the reactor model, the controllability of a particular flowsheet can be evaluated on the basis of the stability margin of design. An interpretation based on the heat-generation and heat-removal curves is also given. With the control lability measure, implications for design are also explored. Because the loss of controllability comes from the positive feedback loop, several design parameters are studied, and design heuristics are proposed to improve the controllability of heat-integration schemes. Two examples, a simple two-FEHE example and an HDA example, are used to assess the controllability of different designs. The results show that, contrary to one's intuition, some of the compl ex heat-integrated reactor design alternatives (e.g., al ternatives 6 and 7 of the HDA example) are indeed more controllable than the simpler heat-integration schemes (e.g., alternative 1). The increased number of FEHEs allows for a greater number of candidate mani pulated inputs and thus provides opportunities for multivariable control. Contrary to one's intuition, the multivariable controlled $\mathrm{FEHE} /$ reactor system gives a steeper slope and a lower peak for the closed-loop load-transfer function. This results in an improved disturbance rejection capability.
\end{abstract}

\section{Introduction}

According to a second-law analysis, the efficiency of the majority of chemical processes ranges from 20 to $30 \% .{ }^{13}$ Thus, there exists an incentive for improvement by heat integration. This is accomplished by controlling energy flows between process streams via heat exchangers. A pproaches include heat exchanger networks ${ }^{11}$ and heat-integrated reactors and columns. ${ }^{9,13}$ An important industrial example is the feed-effluent heat exchanger ( $F E H E)$, where the heat of the exothermic reactions is recovered by preheating the reactor feed. ${ }^{1-3,7,10,14,18}$ Heat-integrated schemes can become very complex when plantwide energy management is taken into consideration [e.g., alternative 6 of the hydrodeal kylation (HDA) process ${ }^{9,15,16}$. Literature examples show that positive feedback makes the plants more difficult to control.9,18 This is an important example of the everpresent tradeoffs and conflicts between steady-state economics and dynamic controllability. The objective of this work is to provide a systematic approach to model and evaluate the dynamic controllability of heatintegrated reactors on the basis of steady-state flowsheets.

* To whom correspondence should be addressed. Tel.: +8862-3365-1759. Fax: +886-2-2362-3040. E-mail: ccyu@ntu.edu.tw.

${ }^{\dagger}$ National Taiwan University of Science and Technology.

‡ National Taiwan University.
Luyben et al. ${ }^{6}$ probably presented the first study of the effect of design on the control of FEHEs. This heatintegrated process is nicely analyzed using the heat generation-removal curve. In this work, a more controloriented approach is taken to look at the interaction between design and control. First, relationships between the degree of heat recovery and open-loop poles are derived. Then, a stability limit for the FEHE, the ultimate heat recovery, is derived analytically. The derivation is then extended to complex FEHE schemes (more than one FEHE), and for different degrees of complexity, a single measure, the overall effectiveness, can be derived. Tradeoffs between heat recovery and system stability can be interpreted with the familiar heat generation-removal plots. Because the stability margin is a good measure of controllability, achievable closed-loop performance can also be evaluated at the design stage. The overall effectiveness provides insight into the controllability analysis, and heuristics for the design of controllable heat-integrated systems are generated accordingly. Two FEHE examples are used to illustrate the closed-loop performance for different designs. The results presented here offer a simple way to synthesize controllable heat-integrated reactors.

Pioneering papers on the control of FEHE systems include those of Douglas et al. ${ }^{3}$ and Silverstein and Shinnar. ${ }^{14}$ Recently, Luyben and co-workers ${ }^{6,8,18}$ ex- 

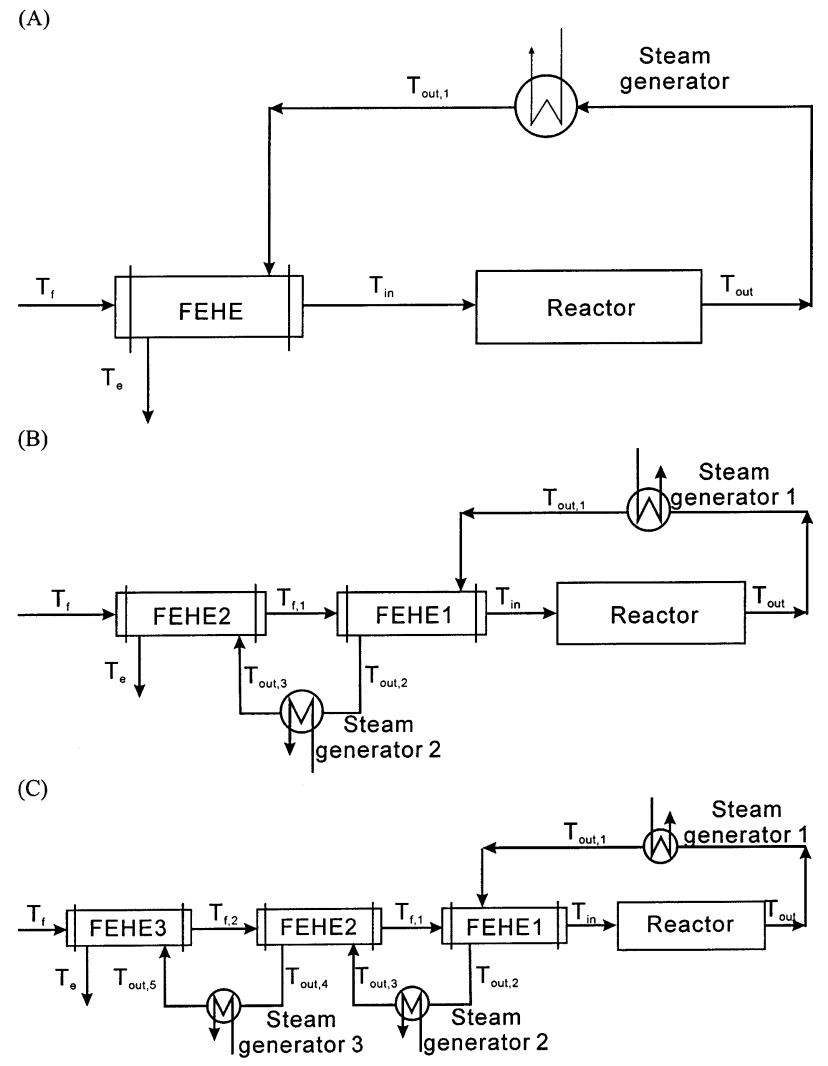

Figure 1. Heat-integrated systems with (A) a single FEHE, (B) dual FEHEs, (C) triple FEHEs.

plored the stability and controller tuning for this positive-feedback system. Chen and $\mathrm{Yu}^{2}$ studied the interaction between thermal efficiency and control of the FEHE system. Seider et al. ${ }^{13}$ and Yan et al. ${ }^{19}$ explored the control of a heat exchanger network in a plantwide framework. All of these literature studies have considered reactors with a single FEHE. The purpose of this paper is to explore the control of more complex heatintegrated schemes, i.e., multiple FEHEs integrated with an adiabatic exothermic reactor.

\section{Feed-Effluent Heat Exchangers (FEHEs)}

In an adiabatic reactor, the heat of the exothermic reactions can be recovered by preheating the feed. A typical example is the feed effluent heat exchanger (FEHE), where the reactor outlet stream ( $\left.T_{\text {out }}\right)$ is used to heat the feed stream $\left(T_{f}\right)$ to the reaction temperature $\left(T_{\text {in }}\right)$, as shown in Figure 1A. As pointed out by several researchers, 1,2,5,10,16,19 the positive feedback nature resulting from the heat recovery makes the simple FEHE scheme (Figure 1A) difficult to control. The process configurations can become even more complex as plantwide energy management is taken into consideration. In the HDA example, Terrill and Douglas ${ }^{15}$ show that, from a heat exchanger network (HEN) analysis, an additional $20-40 \%$ of the energy can be saved, and this results in quite complex schemes in the FEHE. ${ }^{9}$ For example, two or three feed effluent heat exchangers (Figure $1 \mathrm{~B}$ and $1 \mathrm{C}$ ) are required for alternatives 3-6.15 A systematic procedure is necessary for the modeling and analysis of such complex schemes.

2.1. Modeling. The thermodynamic effectiveness $(\epsilon)$ of a heat exchanger was proposed as an important parameter by Kays and London in the 1940 s. ${ }^{4} \mathrm{~F}$ or a heat
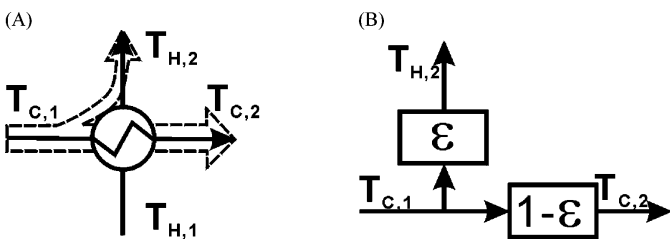

Figure 2. Heat exchanger block diagram representation.

exchanger (Figure 2), the effectiveness is defined as

$$
\epsilon=\frac{\left(m C_{p}\right)_{H}\left(T_{H, 1}-T_{H, 2}\right)}{\left(m C_{p}\right)_{\min }\left(T_{H, 1}-T_{C, 1}\right)}=\frac{\left(m C_{p}\right)_{C}\left(T_{C, 2}-T_{C, 1}\right)}{\left(m C_{p}\right)_{\min }\left(T_{H, 1}-T_{C, 1}\right)}
$$

where $\left(\mathrm{mC}_{\mathrm{p}}\right)_{\mathrm{H}},\left(\mathrm{mC}_{\mathrm{p}}\right)_{\mathrm{c}}$, and $\left(\mathrm{mC}_{\mathrm{p}}\right)_{\min }$ are the capacity flow rates for the hot stream, the cold stream, and the smaller of the two, respectively. Depending on the heattransfer area, $\epsilon$ ranges from 0 (no heat exchangers) to 1 (infinite heat-transfer area). Assuming that the heat capacities of the hot and cold stream are the same, i.e., $C_{p, H}=C_{p, C}$, and because the mass flow rates of the hot and cold streams are identical in an FEHE, eq 1 can be rearranged to give

$$
\begin{aligned}
& \mathrm{T}_{\mathrm{C}, 2}=(1-\epsilon) \mathrm{T}_{\mathrm{C}, 1}+\epsilon \mathrm{T}_{\mathrm{H}, 2} \\
& \mathrm{~T}_{\mathrm{H}, 2}=\epsilon \mathrm{T}_{\mathrm{C}, 1}+(1-\epsilon) \mathrm{T}_{\mathrm{H}, 1}
\end{aligned}
$$

Equations 2 and 3 describe the propagation of the temperature disturbance as the inlet temperature changes, (Figure 2) and they serve as the basic formula for the construction of more complex schemes. Because there is no parallel definition of an effectiveness factor for a steam generator, a modified effectiveness $\left(\epsilon_{\mathrm{ex}}\right)$ is proposed to describe the energy balance for a steam generator (or reboiler). The hot-stream outlet temperature $\left(T_{\mathrm{H}, 2}\right)$ can be expressed in terms of the inlet temperature $\left(T_{H, 1}\right)$ and the steam temperature $\left(T_{H}\right)$ as

$$
\mathrm{T}_{\mathrm{H}, 2}=\left(1-\epsilon_{\mathrm{ex}}\right) \mathrm{T}_{\mathrm{H}, 1}+\epsilon_{\mathrm{ex}} \mathrm{T}_{\mathrm{C}}
$$

Appendix A gives the derivation of this expression.

Consider a simple heat-integrated reactor with an FEHE and a steam generator (Figure $1 A$ ) with effectiveness factors $\epsilon_{1}$ and $\epsilon_{\mathrm{ex}, 1}$, respectively. A block diagram can be constructed according to the flowsheet (Figure 3A)

$$
\begin{aligned}
\mathrm{T}_{\text {in }} & =\left(1-\epsilon_{1}\right) \mathrm{T}_{\mathrm{f}}+\epsilon_{1} \mathrm{~T}_{\text {out }, 1} \\
& =\left(1-\epsilon_{1}\right) \mathrm{T}_{\mathrm{f}}+\epsilon_{1}\left(1-\epsilon_{\mathrm{ex}, 1}\right) \mathrm{T}_{\text {out }} \\
& =\left(1-\epsilon_{1}\right) \mathrm{T}_{\mathrm{f}}+\epsilon_{1}\left(1-\epsilon_{\mathrm{ex}, 1}\right) \mathrm{G}_{\mathrm{R}} \mathrm{T}_{\text {in }}
\end{aligned}
$$

where $T_{f}$ is the feed temperature, $T_{\text {in }}$ stands for the reactor inlet temperature, $T_{\text {out }}$ denotes the reactor outlet temperature, and $\mathrm{T}_{\text {out, } 1}$ represents the exit temperature from the steam generator. $G_{R}$ is the transfer function that describes the reactor outlet temperature as the inlet temperature changes. Rearranging eq 4, we have

$$
\frac{T_{\text {in }}}{T_{f}}=\frac{1-\epsilon_{1}}{1-\epsilon_{1}\left(1-\epsilon_{e x, 1}\right) G_{R}}
$$

This is a positive feedback system, and the loop gain depends on the effectiveness factors $\left(\epsilon_{1}\right.$ and $\left.\epsilon_{\mathrm{ex}, 1}\right)$ and the reactor gain $\left[K_{R}=G_{R}{ }^{(0)}\right]$. For a heat exchanger network (HEN), the loop gain cannot exceed $1\left(\epsilon_{i}\right.$ and 

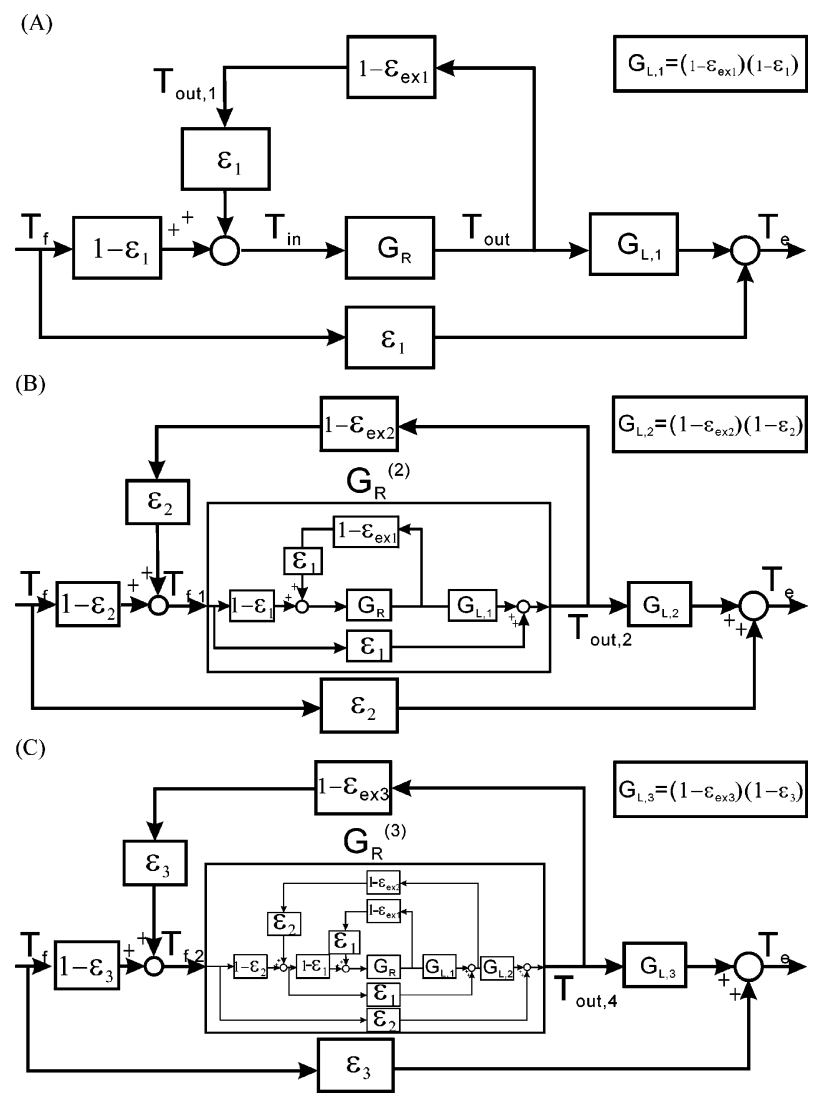

Figure 3. Block diagram of multiple-FEHE heat-integrated system.

products of the $\epsilon_{i}$ 's must always be less than 1 ). However, for a heat-integrated reactor, depending on the reactor gain, the loop gain can exceed unity, and this results in an open-loop unstable system. ${ }^{2,18}$ The stability of this FEHE is determined by the poles of the characteristic equation

$$
1-\epsilon_{1}\left(1-\epsilon_{e x, 1}\right) G_{R}^{(1)}=0
$$

with

$$
\mathrm{G}_{\mathrm{R}}{ }^{(1)}=\mathrm{G}_{\mathrm{R}}
$$

Here, we use $G_{R}{ }^{(1)}$, instead of $G_{R}$, to indicate that there is only one FEHE in this system. We can also derive the exit temperature $\left(T_{e}\right)$ in terms of the feed temperature $\left(\mathrm{T}_{\mathrm{f}}\right)$ (Figure $3 \mathrm{~A}$ ) as

$$
\frac{\mathrm{T}_{\mathrm{e}}}{\mathrm{T}_{\mathrm{f}}}=\epsilon_{1}+\frac{\left(1-\epsilon_{1}\right)^{2}\left(1-\epsilon_{\mathrm{ex}, 1}\right) \mathrm{G}_{\mathrm{R}}{ }^{(1)}}{1-\epsilon_{1}\left(1-\epsilon_{\mathrm{ex}, 1}\right) \mathrm{G}_{\mathrm{R}}{ }^{(1)}}
$$

Please refer to Appendix A for the derivation of this equation (a simple FEHE/reactor system).

The case of a two-FEHE system (Figure 1B) can be viewed, again, as one complete FEHE (Figures $1 \mathrm{~A}$ and $3 A$ ) embedded in another FEHE $\left(\epsilon_{2}\right)$. This provides a systematic procedure for modeling more complex systems, because the same modeling approach (i.e., eqs 4 and 5) can be applied. The relationship between the feed and effluent of a simple FEHE is expressed in eq 8; it can be treated as a single unit in the positive feedback loop, as shown in Figure 3B. We denote this as an extended reactor model (actually a combination of a reactor and an FEHE) at level 2. This is equivalent to deriving the relationship between $\mathrm{T}_{\mathrm{f}, 1}$ and $\mathrm{T}_{\text {out,2 }}$ and the result, certainly, is the same as eq 8

$$
\mathrm{G}_{\mathrm{R}}{ }^{(2)}=\frac{\mathrm{T}_{\text {out }, 2}}{\mathrm{~T}_{\mathrm{f}, 1}}=\epsilon_{1}+\frac{\left(1-\epsilon_{1}\right)^{2}\left(1-\epsilon_{\mathrm{ex}, 1}\right) \mathrm{G}_{\mathrm{R}}{ }^{(1)}}{1-\epsilon_{1}\left(1-\epsilon_{\mathrm{ex}, 1}\right) \mathrm{G}_{\mathrm{R}}{ }^{(1)}}
$$

The superscript (2) denotes the extended reactor model for the case of two FEHEs. Again, the characteristic equation is simply

$$
1-\epsilon_{2}\left(1-\epsilon_{e x, 2}\right) G_{R}^{(2)}=0
$$

The same principle applies to the case of three FEHEs (Figures $1 \mathrm{~A}$ and $3 \mathrm{~A}$ ). Here, two FEHEs are embedded in the positive feedback loop, resulting in an extended reactor model at level 3 . That is

$$
\mathrm{G}_{\mathrm{R}}{ }^{(3)}=\epsilon_{2}+\frac{\left(1-\epsilon_{2}\right)^{2}\left(1-\epsilon_{\mathrm{ex}, 2}\right) \mathrm{G}_{\mathrm{R}}{ }^{(2)}}{1-\epsilon_{2}\left(1-\epsilon_{\mathrm{ex}, 2}\right) \mathrm{G}_{\mathrm{R}}{ }^{(2)}}
$$

The characteristic equation becomes

$$
1-\epsilon_{3}\left(1-\epsilon_{\mathrm{ex}, 3}\right) \mathrm{G}_{\mathrm{R}}{ }^{(3)}=0
$$

We can generalize the derivation to the case of $n$ FEHEs. First, the extended reactor model at level $n$ is

$$
\mathrm{G}_{\mathrm{R}}^{(\mathrm{n})}=\epsilon_{\mathrm{n}-1}+\frac{\left(1-\epsilon_{\mathrm{n}-1}\right)^{2}\left(1-\epsilon_{\mathrm{ex}, \mathrm{n}-1}\right) \mathrm{G}_{\mathrm{R}}{ }^{(\mathrm{n}-1)}}{1-\epsilon_{\mathrm{n}-1}\left(1-\epsilon_{\mathrm{ex}, \mathrm{n}-1}\right) \mathrm{G}_{\mathrm{R}}{ }^{(\mathrm{n}-1)}}
$$

and the associated characteristic equation is

$$
1-\epsilon_{\mathrm{n}}\left(1-\epsilon_{\mathrm{ex}, \mathrm{n}}\right) \mathrm{G}_{\mathrm{R}}^{(\mathrm{n})}=0
$$

With this general formulation (i.e., eqs 13 and 14), we are able to assess the stability for complex FEHE systems.

Before leaving this section, it should be noted that the complex network in Figure 1 (e.g., 1C) actually is quite similar to the heat-integration scheme of industrial processes. For example, in alternative 6 of Terrill and Douglas (shown bel ow in Figure 20B), the reboilers in Figure 1C provide heat input to the recycle column, to the stabilizer, and then to the product column. In other words, the network presented in Figure $1 \mathrm{C}$ is generic, and it describes the heat-integration between FEHE and process units. More importantly, a complex network can be model as a simple FEHE scheme in a repeated manner.

2.2. Controllability. 2.2.1. Overall Effectiveness. The poles and zeros play an important role in the inherent controllability of FEHE systems. The characteristic equation, eq 14, describes the pole locations for systems with $n$ FEHEs, and $G_{R}{ }^{(n)}$ can be expressed explicitly in terms of $\epsilon_{n-1}$ and $G_{R}{ }^{(n-1)}$ (eq 13). Therefore, we can go back to the previous layer and derive the stability criterion explicitly in terms of all of the $\epsilon_{\mathrm{i}}$ 's. Substituting $G_{R}{ }^{(n-1)}$ for $G_{R}{ }^{(n)}$, eq 13 becomes the expression shown in eq 15. Going back a step further, one obtains eq 16.

Repeating this procedure, we can express $G_{R}{ }^{(n)}$ explicitly in terms of $G_{R}{ }^{(1)}$ (i.e., $G_{R}$ and the $\epsilon_{i}$ 's). For 


$$
\begin{aligned}
& \mathrm{G}_{\mathrm{R}}{ }^{(\mathrm{n})}=\epsilon_{\mathrm{n}-1}+\frac{\left(1-\epsilon_{\mathrm{n}-1}\right)^{2}\left(1-\epsilon_{\mathrm{ex}, \mathrm{n}-1}\right)\left[\epsilon_{\mathrm{n}-2}+\frac{\left(1-\epsilon_{\mathrm{n}-2}\right)^{2}\left(1-\epsilon_{\mathrm{ex}, \mathrm{n}-2}\right) \mathrm{G}_{\mathrm{R}}{ }^{(\mathrm{n}-2)}}{1-\epsilon_{\mathrm{n}-2}\left(1-\epsilon_{\mathrm{ex}, \mathrm{n}-2}\right) \mathrm{G}_{\mathrm{R}}{ }^{(\mathrm{n}-2)}}\right]}{1-\epsilon_{\mathrm{n}-1}\left(1-\epsilon_{\mathrm{ex}, \mathrm{n}-1}\right)\left[\epsilon_{\mathrm{n}-2}+\frac{\left(1-\epsilon_{\mathrm{n}-2}\right)^{2}\left(1-\epsilon_{\mathrm{ex}, \mathrm{n}-2}\right) \mathrm{G}_{\mathrm{R}}{ }^{(\mathrm{n}-2)}}{1-\epsilon_{\mathrm{n}-2}\left(1-\epsilon_{\mathrm{ex}, \mathrm{n}-2}\right) \mathrm{G}_{\mathrm{R}}{ }^{(\mathrm{n}-2)}}\right]}
\end{aligned}
$$

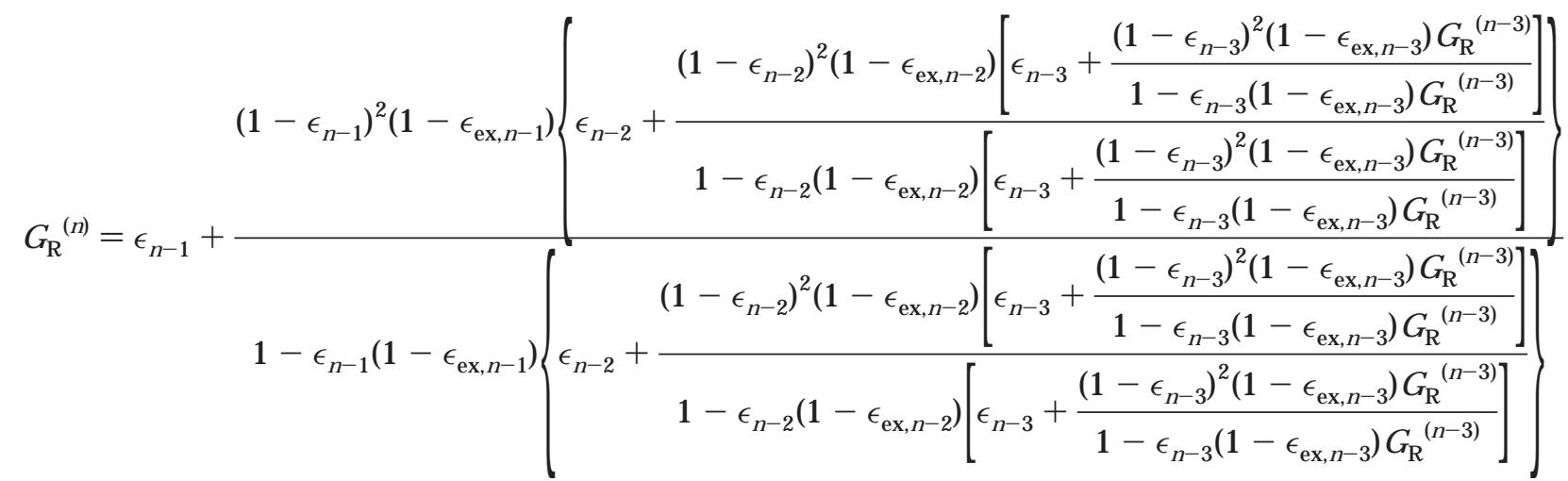

example, for the case of a dual FEHE, the extended reactor model becomes

$$
\mathrm{G}_{\mathrm{R}}{ }^{(2)}=\epsilon_{1}+\frac{\left(1-\epsilon_{1}\right)^{2}\left(1-\epsilon_{\mathrm{ex}, 1}\right) \mathrm{G}_{\mathrm{R}}{ }^{(1)}}{1-\epsilon_{1}\left(1-\epsilon_{\mathrm{ex}, 1}\right) \mathrm{G}_{\mathrm{R}}{ }^{(1)}}
$$

Substitution of eq 17 into the characteristic equation (eq 10) gives

$$
1-\epsilon_{2}\left(1-\epsilon_{\mathrm{ex}, 2}\right)\left[\epsilon_{1}+\frac{\left(1-\epsilon_{1}\right)^{2}\left(1-\epsilon_{\mathrm{ex}, 1}\right) \mathrm{G}_{\mathrm{R}}{ }^{(1)}}{1-\epsilon_{1}\left(1-\epsilon_{\mathrm{ex}, 1}\right) \mathrm{G}_{\mathrm{R}}{ }^{(1)}}\right]=0
$$

Rearranging eq 18, the characteristic equation becomes

$$
1-\frac{\epsilon_{1}\left(1-\epsilon_{\mathrm{ex}, 1}\right)+\epsilon_{2}\left(1-\epsilon_{\mathrm{ex}, 2}\right)\left(1-2 \epsilon_{1}\right)\left(1-\epsilon_{\mathrm{ex}, 1}\right)}{1-\epsilon_{1} \epsilon_{2}\left(1-\epsilon_{\mathrm{ex}, 2}\right)} \mathrm{G}_{\mathrm{R}}=0
$$

Equation 19 reveals that, as for a simple FEHE, the pole locations are determined by two separate factors: one contains all of the $\epsilon_{i}$ 's, and the other is $G_{R}$. We now define the overall effectiveness (at level 2 ) as

$$
\epsilon_{\mathrm{o}}{ }^{(2)}=\frac{\epsilon_{1}\left(1-\epsilon_{\mathrm{ex}, 1}\right)+\epsilon_{2}\left(1-\epsilon_{\mathrm{ex}, 2}\right)\left(1-2 \epsilon_{1}\right)\left(1-\epsilon_{\mathrm{ex}, 1}\right)}{1-\epsilon_{1} \epsilon_{2}\left(1-\epsilon_{\mathrm{ex}, 2}\right)}
$$

Thus, the characteristic equation for the case of a dual FEHE is simply

$$
1-\epsilon_{0}{ }^{(2)} \mathrm{G}_{\mathrm{R}}=0
$$

Table 1 gives the overall effectiveness factors for the cases of one, two, and three FEHEs $\left(\epsilon_{0}{ }^{(i)}, i=1,2,3\right)$. Therefore, we can assess the stability of more complex schemes by evaluating the overall effectiveness.

2.2.2. Stability Margin. In other words, we can locate the poles of complex FEHE schemes by treating them as a simple positive feedback loop provided with the corresponding overall effectiveness (Table 1). Con- sider a reactor model that relates $\mathrm{T}_{\text {in }}$ to $\mathrm{T}_{\text {out }}$ (e.g., $\mathrm{F}$ igure 3A)

$$
\mathrm{G}_{\mathrm{R}}(\mathrm{s})=\frac{\mathrm{T}_{\text {out }}}{\mathrm{T}_{\text {in }}}=\frac{\mathrm{K}_{\mathrm{R}}}{\tau \mathrm{s}+1}
$$

Here, $K_{R}$ is the steady-state gain, and $\tau$ is the time constant. Generally, as we try to recover more heat, the overall effectiveness increases, and the positive feedback system tends to become less stable [i.e., the pol es move toward the right half-plane (RHP) ${ }^{2}$. The limit of stability can be found by solving the characteristic equation (i.e., eq 21) provided with the reactor model (eq 22)

$$
\begin{aligned}
1-\epsilon \mathrm{G}_{\mathrm{R}} & =1-\epsilon \frac{\mathrm{K}_{\mathrm{R}}}{\tau \mathrm{S}+1} \\
& =\frac{\tau \mathrm{S}+1-\epsilon \mathrm{K}_{\mathrm{R}}}{\tau \mathrm{S}+1}=0
\end{aligned}
$$

From eq 23, it is clear that the ultimate effectiveness $\left(\epsilon_{\mathrm{u}}\right)$ is simply the inverse of the reactor gain $\left[K_{R}=G_{R}{ }^{(0)}\right]$ Therefore, we can evaluate the stability of FEHEs at

$$
\epsilon_{\mathrm{u}}=\frac{1}{\mathrm{~K}_{\mathrm{R}}}
$$

different levels of complexity using the overall effectiveness

$$
\epsilon_{\mathrm{o}}^{(\mathrm{i})} \begin{cases}>\frac{1}{\mathrm{~K}_{\mathrm{R}}} & \text { unstable } \\ =\frac{1}{\mathrm{~K}_{\mathrm{R}}} & \text { limit of stability } \\ <\frac{1}{\mathrm{~K}_{\mathrm{R}}} & \text { stable }\end{cases}
$$

Note that the applicability of eq 25 is not limited to the first-order reactor model only; it is valid for any stable reactor model with nonincreasing magnitude in $\mathrm{G}_{\mathrm{R}}(\mathrm{iw})$. This can be proved from the Nyquist stability criterion, following Tyreus and Luyben. ${ }^{18}$ From the characteristic equation ( $\left.1-\epsilon_{0}{ }^{(i)} G_{R}=0\right)$, a stable FEHE requires that the Nyquist pl ot of $\mathrm{G}_{R}(\mathrm{iw})$ does not encircle 
Table 1. Structure Effect on Overall Effectiveness

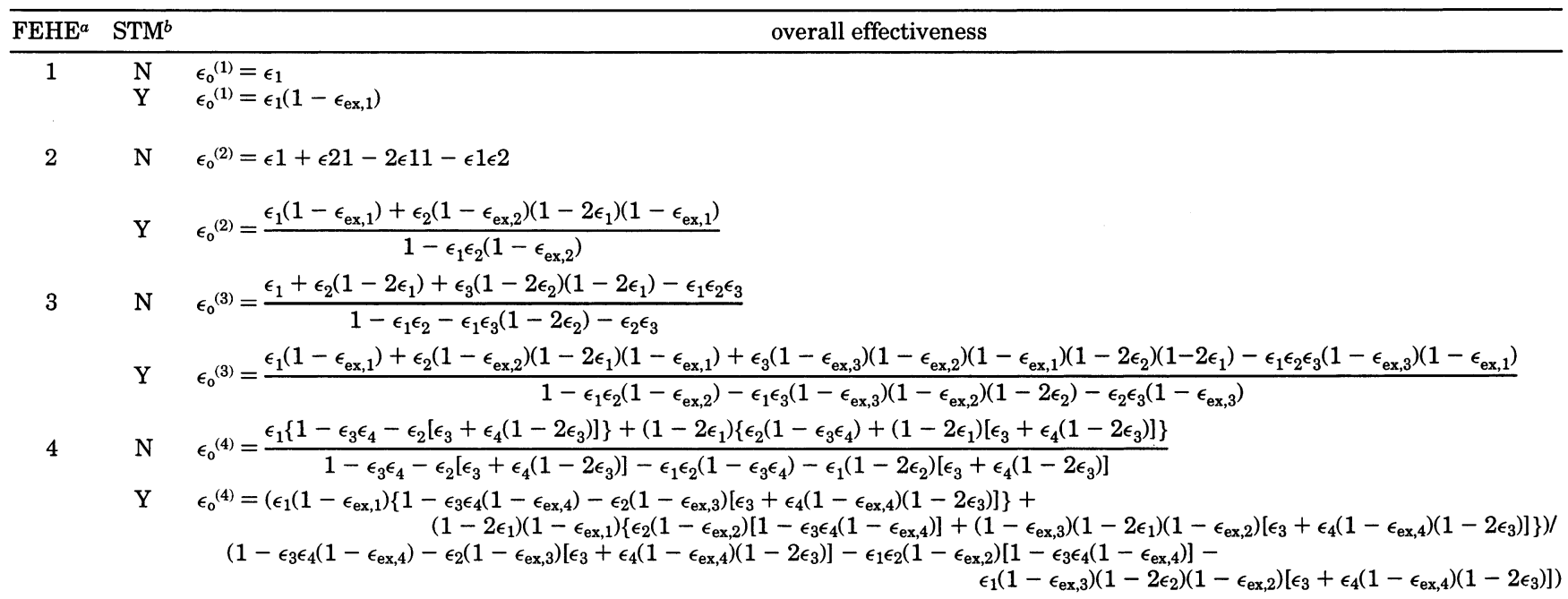

a Number of FEHEs. ${ }^{b}$ Steam generator used.

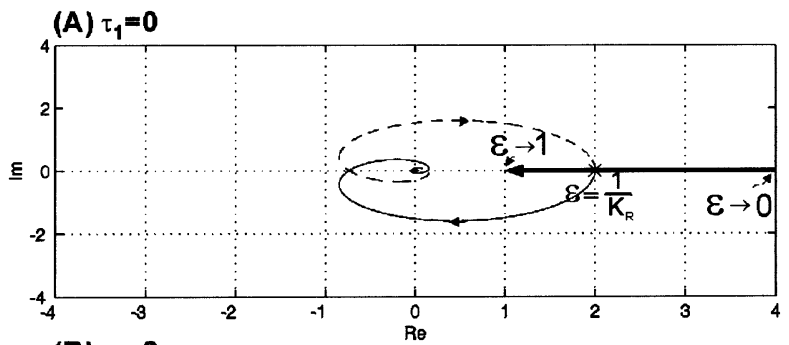

(B) $\tau_{1}=2$
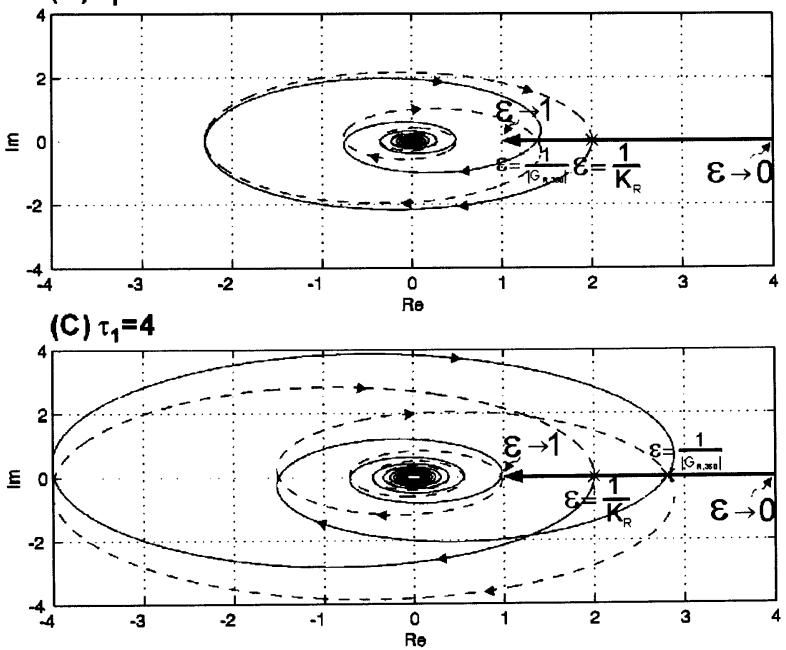

Figure 4. Nyquist pole location plot for a PFR reactor wrongway behavior.

$1 / \epsilon_{0}{ }^{(i)}$. Because $G_{R}$ is stable and the magnitude of $\mid G_{R^{-}}$ (iw)| is a nonincreasing function, the limit of stability is

$$
\frac{1}{\epsilon_{0}{ }^{(i)}}=G_{R}{ }^{(0)}=K_{R}
$$

If we increase $\epsilon_{0}^{(i)}$ further, e.g., $\epsilon_{0}^{(i)}=1 / K_{R}$ in Figure 4A, $\mathrm{G}_{\mathrm{R}}(\mathrm{iw})$ encircles $1 / \epsilon_{\mathrm{O}}{ }^{(\mathrm{i})}$, and the FEHE system becomes unstable.

Instead of choosing the stability of any given design, we would like to have a quantitative measure for $F E H E$ designs. The familiar gain margin (GM) is used for the following reasons: Most design modification is reflected in the overall effectiveness, which affects only the gain in the characteristic equation. Given the characteristic equation and specifications on $G_{R}$, the gain margin for a general FEHE is

$$
\mathrm{GM}=\frac{\epsilon_{\mathrm{u}}}{\epsilon_{\mathrm{o}}^{(\mathrm{i})}}=\frac{1 / \mathrm{K}_{\mathrm{R}}}{\epsilon_{\mathrm{o}}^{(\mathrm{i})}}
$$

Similarly to the familiar rules for the GM, an FEHE design is stable if the GM is greater than 1, and the FEHE becomes unstable if the GM is less than 1. This is useful in evaluating controllability for FEHEs.

Because an inverse response (wrong-way behavior) is sometimes observed in packed-bed reactors, this generally results in an RHP zero in the reactor model. For example, consider the following reactor model

$$
\mathrm{G}_{\mathrm{R}}(\mathrm{s})=\frac{\mathrm{K}_{\mathrm{R}}\left(-\tau_{1} \mathrm{~S}+1\right) \mathrm{e}^{-\mathrm{Ds}}}{(\tau \mathrm{s}+1)^{2}}
$$

The model structure in eq 28 gives a nonmonotonic behavior in the magnitude of $\left|G_{R}(i w)\right|$, and this might further limit the stability range (amount of heat that can be recovered) for $\mathrm{FEHES} .{ }^{10,18}$ The reason for this is that the frequency response of $\mathrm{G}_{\mathrm{R}}(\mathrm{iw})$ at $-360^{\circ}$ can cross the positive real axis further to the right than the steady-state gain $\left(0^{\circ}\right)$ (e.g., Figure $4 C$ ). F or example, for a system with $\tau=1$ and $\mathrm{D}=1$ (eq 28), if we increase $\tau_{1}$ (move the RHP zero toward the origin), the limit of stability becomes $1 /\left|\mathrm{G}_{\mathrm{R}}(360)\right|$ (instead of the inverse of the magnitude when the phase is $-360^{\circ}$ ), which is less than $1 / K_{R}$, as shown in Figure 4 . This complicates the stability analysis because we need dynamic information on $\mathrm{G}_{R}(\mathrm{~s})$ instead of $\mathrm{G}_{\mathrm{R}}(0)$ only. Figure 4 also reveals that inverse-response systems will deteriorate in the stability range only if $\left|G_{R}(360)\right|>K_{R}$.

The gain margin for the design then becomes

$$
\mathrm{GM}=\min _{\mathrm{n}} \frac{1 /\left|\mathrm{G}_{\mathrm{R}}(360 \mathrm{n})\right|}{\epsilon_{\mathrm{o}}{ }^{(\mathrm{i})}}
$$

That is, instead of looking at steady-state value of $G_{R}$, we have to find the largest magnitude of $G_{R}(i w)$ when it crosses the positive real axis (i.e., all phase angles are integer multiple of $360^{\circ}$, including $n=0$ ). It should be noticed that, throughout the derivation, we have 


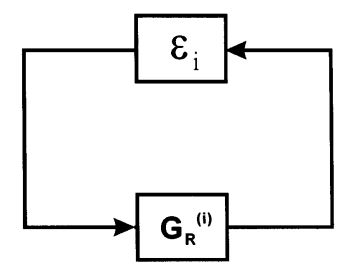

Figure 5. Pole and zero exchange in positive feedback system.

assumed that the heat exchanger dynamics is much faster than that of the reactor. This is a reasonable assumption for most FEHE/reactor systems. However, in some occasions, the heat exchanger dynamics might be significant, and all dynamics associated with FEHEs $(\epsilon$ 's) should be accounted for in the stability analysis (e.g., eq 21). Nonetheless, with the definition of the GM, we are able to quantify the degree of controllability for FEHE systems with different levels of complexity.

Up to this point, we have provided a procedure to find the pole location (or stability margin) for FEHE systems. The positive feedback system (e.g., Figure 3) shows a unique mechanism for pole-zero exchange, and this has important implications for layered FEHE structures (Figure 3). Consider the typical positive feedback system depicted in Figure 5 with $G_{R}{ }^{(i)}=n^{(i)} / d^{(i)}$, where $n^{(i)}$ is the numerator polynomial and $\mathrm{d}^{(\mathrm{i})}$ is the denominator polynomial for the generalized reactor model. The return difference transfer function becomes

$$
\frac{1}{1-\epsilon_{i} G_{R}^{(i)}}=\frac{1}{1-\epsilon_{i} \frac{n_{i}^{(i)}}{d_{i}^{(i)}}}=\frac{d_{i}^{(i)}}{d_{i}^{(i)}-\epsilon_{i} n_{i}^{(i)}}
$$

Equation 30 clearly indicates that the poles of $G_{R}{ }^{(i)}$ (i.e., $d^{(i)}=0$ ) become the zeros (i.e., $d_{i}^{(i)}=0$ ) of the positive feedback system. For the layered structure shown in Figure 3, this means that the pol es of $G_{R}{ }^{(1)}$ becomes the zeros of $G_{R}{ }^{(2)}$ and the poles of $G_{R}{ }^{(2)}$ become the zeros of $\mathrm{G}_{R}{ }^{(3)}$. Thus, the sequence in arranging $\epsilon_{\mathrm{i}}$ 's and $\epsilon_{\mathrm{ex}, \mathrm{i}}$ 's becomes important. For dual-FEHE system (Figure 3B), if we design a relatively large $\epsilon_{1}$ (i.e., $\epsilon_{1}>\epsilon_{\mathrm{u}}$ ) that leads to an unstable $G_{R}{ }^{(2)}$, then the system in Figure $3 B$ will have positive poles as well as positive (RHP) zeros. This is, of course, undesirable, but it can provide useful guidel ines for avoiding uncontrollable designs.

\section{Implications for Design}

Provided with the overall effectiveness, we are able to evaluate the stability margin for any given FEHE system. Using the GM of the design, we can assess the appropriateness of different FEHE systems. Before getting into the details, the following definitions are useful to the subsequent devel opment:

$\mathrm{Q}_{\mathrm{FEHE}}$ is the heat recovered by feed effluent heat exchangers $\left(\epsilon_{\mathrm{i}}\right.$ in Figure 1$)$.

QstM is the heat recovered by steam generator $\left(\epsilon_{\mathrm{ex}, \mathrm{i}}\right.$ in Figure 1).

$Q_{R E C}$ is the sum of the heat recovered by the FEHES and the reboilers $\left(Q_{\mathrm{REC}}=\mathrm{Q}_{\mathrm{FEHE}}+\mathrm{Q}_{\mathrm{STM}}\right)$.

QFUR is the heat supplied to the furnace (Figure 6).

The following assumptions are also made. First, the heat-capacity flow rates are constants $\left[\left(\mathrm{mC}_{\mathrm{p}}\right)_{\mathrm{H}}=\left(\mathrm{mC}_{\mathrm{p}}\right)_{\mathrm{C}}\right]$. Second, the feed temperature $\left(T_{f}\right)$ and the inlet temper-

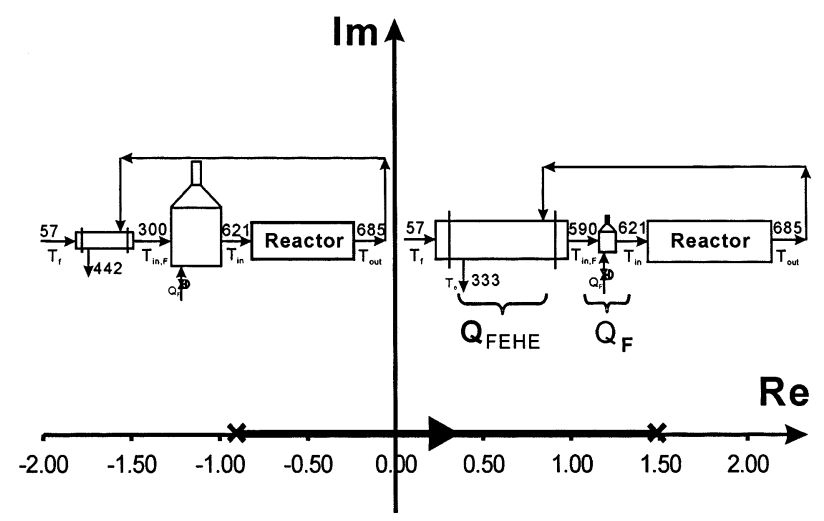

Figure 6. Root location for different energy recoveries.

ature of the reactor $\left(T_{\text {in }}\right)$ are kept constant for different designs, which implies that $\mathrm{Q}_{\mathrm{REC}}=\mathrm{Q}_{\mathrm{FEHE}}+\mathrm{Q}_{\mathrm{STM}}$ is also constant.

3.1. Size of FEHE. For a system with fixed $T_{f}$ and $\mathrm{T}_{\text {in }}$ (Figure 8), a large FEHE (i.e., $\mathrm{Q}_{\mathrm{FEHE}}$ ) implies a small furnace (i.e., QfuR) and vice versa. This case was first studied by Luyben et al. ${ }^{9}$ and analyzed by Chen and $\mathrm{Yu}^{2}$ As one tries to heat the inlet stream using primarily the FEHE, the result is a larger $\mathrm{Q}_{F E H E}$ and, consequently, a larger overall effectiveness $\left(\epsilon_{0}\right)$. Therefore, the stability margin (eq 27) decreases as one tries to recover more heat from the FEHE (Q result can be obtained by inspecting the open-loop pole of the positive feedback system. For the simple firstorder reactor model in eq 22 , the open-loop pole is given by

$$
\mathrm{p}=\frac{-1+\epsilon_{\mathrm{o}} \mathrm{K}_{\mathrm{R}}}{\tau}
$$

Therefore, an increase in $\epsilon_{\mathrm{o}}$ moves the pole toward the RHP (Figure 6). This is al ways true irrespective of the complexity of the FEHEs, because, here, only the magnitude of the overall effectiveness matters.

Consider the following reactor model

$$
\mathrm{G}_{\mathrm{R}}(\mathrm{s})=\frac{2.5}{0.47 \mathrm{~s}+1}
$$

If the FEHE accounts for $25 \%$ of the energy required to heat the reactant, one obtains

$$
\epsilon_{\mathrm{o}}=\epsilon_{1}=\frac{200-57}{685-57}=0.23
$$

The pole of the positive feedback system is located at $p$ $=-0.90$, as shown in Figure 6. If we increase the size of the FEHE to provide $95 \%$ of the energy for the preheating, the effectiveness becomes $\epsilon=0.85$, and the system becomes open-loop unstable (i.e., $p=1.49$, Figure 6).

Figure 7A illustrates the effect of the size of the FEHE on the temperature-enthalpy $(\mathrm{T}-\mathrm{H})$ diagram for the system. This is a simplified version of the HDA example, and the numerical values for stream temperatures are given in Table 2 (cases A1-A3). As one tries to recover more heat via the FEHE, the minimum approach temperature $\left(\Delta T_{\min }\right)$ becomes smaller, and a larger proportion of the heat is recovered, as shown in $\mathrm{T}-\mathrm{H}$ diagram. Moving from left to right in Figure 7A, $\epsilon_{0}$ becomes larger, and the pole moves toward the RHP. 

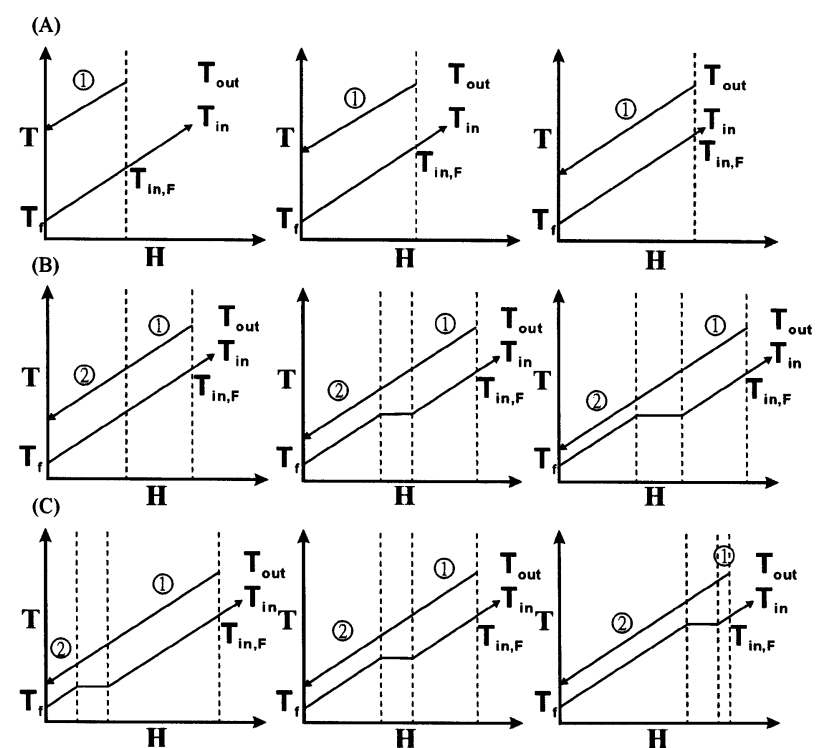

Figure 7. $\mathrm{T}-\mathrm{H}$ diagram for changes in (A) FEHE size, (B) STM size, (C) size of two FEHEs.

Table 2. Stream Data for Figure 7

\begin{tabular}{|c|c|c|c|c|c|c|c|c|c|}
\hline & & ream & $\begin{array}{l}\text { supply } \\
\text { temp }\end{array}$ & $\begin{array}{l}\text { target } \\
\text { temp }\end{array}$ & $\Delta T_{\min }$ & & & & $\begin{array}{c}\text { overall } \\
\text { effectiveness }\end{array}$ \\
\hline & no. & type & & & $\left({ }^{\circ} \mathrm{C}\right)$ & $\epsilon_{1}$ & $\epsilon_{2}$ & $\epsilon_{\mathrm{ex}, 2}$ & \\
\hline Al & $\begin{array}{l}1 \\
2\end{array}$ & $\begin{array}{l}\text { hot } \\
\text { cold }\end{array}$ & $\begin{array}{r}685 \\
57\end{array}$ & $\begin{array}{l}550 \\
200\end{array}$ & $\begin{array}{c}\text { case A } \\
493\end{array}$ & 0.23 & & & 0.23 \\
\hline A2 & $\begin{array}{l}1 \\
2\end{array}$ & $\begin{array}{l}\text { hot } \\
\text { cold }\end{array}$ & $\begin{array}{r}685 \\
57\end{array}$ & $\begin{array}{l}213 \\
529\end{array}$ & 156 & 0.75 & & & 0.75 \\
\hline A3 & $\begin{array}{l}1 \\
2\end{array}$ & $\begin{array}{l}\text { hot } \\
\text { cold }\end{array}$ & $\begin{array}{r}685 \\
57\end{array}$ & $\begin{array}{l}152 \\
590\end{array}$ & 95 & 0.85 & & & 0.85 \\
\hline B1 & $\begin{array}{l}1 \\
2 \\
3\end{array}$ & $\begin{array}{l}\text { hot } \\
\text { cold } \\
\text { STM }^{a}\end{array}$ & $\begin{array}{r}685 \\
57 \\
338\end{array}$ & $\begin{array}{r}213 \\
529 \\
8^{b}\end{array}$ & $\begin{array}{c}\text { case B } \\
156\end{array}$ & 0.55 & 0.64 & 0 & 0.75 \\
\hline B2 & $\begin{array}{l}1 \\
2 \\
3\end{array}$ & $\begin{array}{l}\text { hot } \\
\text { cold } \\
\text { STM }^{a}\end{array}$ & $\begin{array}{r}685 \\
57 \\
338\end{array}$ & $\begin{array}{r}173 \\
529 \\
8 \mathrm{C}\end{array}$ & 116 & 0.55 & 0.71 & 0.26 & 0.70 \\
\hline B3 & $\begin{array}{l}1 \\
2 \\
3\end{array}$ & $\begin{array}{l}\text { hot } \\
\text { cold } \\
\text { STMa }^{a}\end{array}$ & $\begin{array}{c}685 \\
57 \\
338\end{array}$ & $\begin{array}{r}133 \\
529 \\
8^{d}\end{array}$ & 76 & 0.55 & 0.78 & 0.51 & 0.65 \\
\hline $\mathrm{Cl}$ & $\begin{array}{l}1 \\
2 \\
3\end{array}$ & $\begin{array}{l}\text { hot } \\
\text { cold } \\
\text { STM }^{2}\end{array}$ & $\begin{array}{l}685 \\
57 \\
110\end{array}$ & $\begin{array}{r}133 \\
529 \\
0^{d}\end{array}$ & $\begin{array}{c}\text { case C } \\
76\end{array}$ & 0.73 & 0.41 & 0.51 & 0.75 \\
\hline C2 & $\begin{array}{l}1 \\
2 \\
3\end{array}$ & $\begin{array}{l}\text { hot } \\
\text { cold } \\
\text { STMe }\end{array}$ & $\begin{array}{r}685 \\
57 \\
164\end{array}$ & $\begin{array}{r}133 \\
529 \\
4^{d}\end{array}$ & 76 & 0.70 & 0.58 & 0.51 & 0.73 \\
\hline C3 & $\begin{array}{l}1 \\
2 \\
3\end{array}$ & $\begin{array}{l}\text { hot } \\
\text { cold } \\
\text { STMe }\end{array}$ & $\begin{array}{l}685 \\
57 \\
338\end{array}$ & $\begin{array}{r}133 \\
529 \\
8^{d}\end{array}$ & 76 & 0.55 & 0.79 & 0.51 & 0.65 \\
\hline
\end{tabular}

a Steam generator used. ${ }^{\mathrm{b}} \mathrm{Q}_{\text {STM }}=0 .{ }^{\mathrm{c}} \mathrm{Q}_{\text {STM }}=40 .{ }^{\mathrm{d}} \mathrm{Q}_{\text {STM }}=80$. e Steam generator used.

3.2. Size of Steam Generator $\left(\mathbf{Q}_{\mathrm{stm}}\right)$. Consider the case in which we would like to recover additional heat from the reactor effluent, but unlike in the previous case, we integrate the heat away from the positive feedback loop, e.g., by providing steam to the reboiler of a distillation column. The flowsheets in Figure 8 show cases in which two FEHEs provide the same amount of energy for preheating (84\%). For the first FEHE, the effectiveness can be computed according to eq 1 to give

$$
\epsilon_{1}=\frac{529-338}{685-338}=0.55
$$

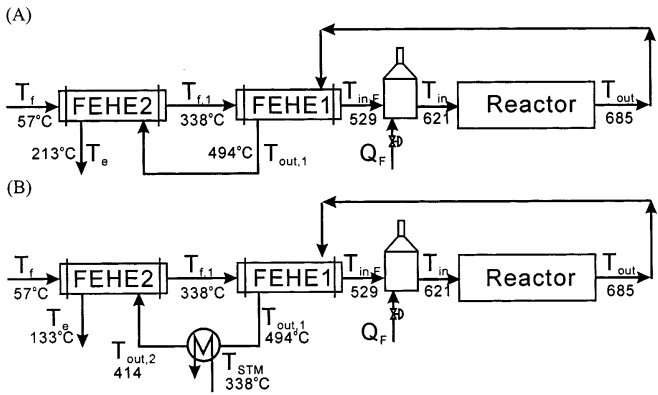

Figure 8. Heat-integrated system flowsheet (A) without steam generator, (B) with steam generator.

Given the boilup temperature, the effectiveness of the reboiler can also be calculated as

$$
\epsilon_{\mathrm{ex}, 2}=\frac{494-414}{494-338}=0.51
$$

From Table 1, the overall effectiveness becomes (for case B3 of Table 2)

$$
\epsilon_{\mathrm{o}}^{(2)}=\frac{0.55+0.78[1-(2)(0.55)](1-0.51)}{1-(0.55)(0.78)(1-0.51)}=0.65
$$

Similarly, we can also compute the overall effectiveness for the case with no reboiler (case B1 of Table 2). The result is $\epsilon_{0}^{(2)}=0.75$ (Table 2 ), which is larger than the overall effectiveness for the case with a reboiler. Given a reactor gain of $K_{R}=1.36$, we can compute the gain margin for both designs, and the results are

$$
\begin{gathered}
(\mathrm{GM})_{\mathrm{w} / \mathrm{o}}=\frac{1 / \mathrm{K}_{\mathrm{R}}}{\epsilon_{\mathrm{o}}^{(2)}}=\frac{1 / 1.36}{0.75}=0.98 \\
(\mathrm{GM})_{\mathrm{w}}=\frac{1 / \mathrm{K}_{\mathrm{R}}}{\epsilon_{\mathrm{o}}^{(2)}}=\frac{1 / 1.36}{0.65}=1.13
\end{gathered}
$$

The results indicate that the system becomes stable (e.g., GM = 1.13), if we recover heat from the reactor effluent via a steam generator. This is exactly the opposite of what we learned in the previous section, but the reason is quite obvious: we integrate the heat away from the positive feedback loop. This can also be seen from the equations in Table 1 , which indicate that a larger value in $\epsilon_{\mathrm{ex}, 1}$ or $\epsilon_{\mathrm{ex}, 2}$ (i.e., recovery of more heat via the steam generator) leads to a smaller overall effectiveness. This also implies that, contrary to intuition, a complex heat-integrated plant, such as alternative 6 of the HDA process, can be more controllable, at least from the stability point of view.

The $\mathrm{T}-\mathrm{H}$ diagrams in Figure $7 \mathrm{~B}$ reveal that, when the plateau becomes larger (moving from left to right in Figure 7B), the overall effectiveness becomes smaller, and the heat-integrated system becomes more controllable (case B in Table 2).

3.3. Temperature of Steam Generation ( $\mathrm{T}_{\mathrm{STM}}$ ). The previous section indicates that, if a large amount of heat is recovered via a steam generator, the system tends to become stable. N ow consider the case when the same amount of heat, QsTM, is recovered, but at different temperature levels. Figure 9 shows the flowsheets where steam is generated at 110 and $338{ }^{\circ} \mathrm{C}$. N ote that 


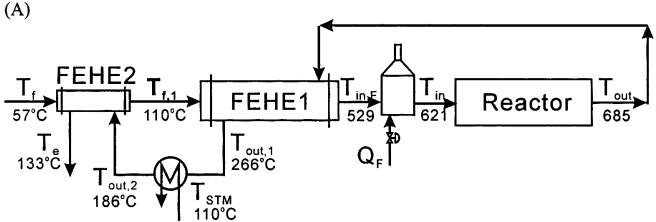

(B)

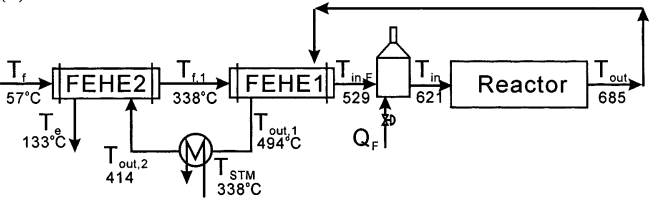

Figure 9. Heat-integrated system flowsheet.

the change in temperature changes the relative size of the two FEHEs. If steam is generated at a higher temperature (e.g., $\mathrm{T}_{\text {STM }}=338^{\circ} \mathrm{C}$ in Figure 9B), the first FEHE $\left(\epsilon_{1}\right)$ is smaller and is followed by a larger second FEHE $\left(\epsilon_{2}\right)$, as shown in Table 3. Considering the other case where the heat is removed at a much lower temperature, i.e., $\mathrm{T}_{\mathrm{STM}}=110^{\circ} \mathrm{C}$, the configuration is reversed to a large $F$ EHE followed by a smaller one, as shown in Figure 9A. The results show that, if the steam is generated at a higher temperature, $\epsilon_{0}$ is smaller, and consequently, the system is more stable (Table 3). The reason for this is that, in the flowsheet in Figure 9A, a larger portion of the heat is immediately fed back to the reactor because of the large $\epsilon_{1}$ value and, moreover, the energy recycled back to the reactor via the second FE HE $\left(\epsilon_{2}\right)$ is discounted by the steam generator. On the other hand, the configuration in Figure 9B recycles a smaller portion of energy back to the reactor first (via $\epsilon_{1}$ ) and then uses a larger FE HE after the steam generator, and this leads to a smaller $\epsilon_{0}$. This can also be seen from eq 20 (Table 1), where the effect of $\epsilon_{2}$ on the overall effectiveness is discounted by a factor of $\left(1-\epsilon_{\mathrm{ex}, 2}\right)$, which is always less than 1 , whereas $\epsilon_{1}$ still has its original direct effect on $\epsilon_{0}$.

Moreover, a larger $\epsilon_{1}$ (e.g., Figure 9A) is al so unfavorable because of pole-zero exchange. As pointed out earlier, the pole of the inner layer becomes the zero of the outer layer, and therefore, a larger $\epsilon_{1}$ implies the possibility of an RHP zero. For example, consider the following reactor model

$$
\mathrm{G}_{\mathrm{R}}(\mathrm{s})=\frac{1.73}{0.47 \mathrm{~s}+1}
$$

The pole (p) and zero (z) for the case of Figure 9A (case $\mathrm{C} 1$ in Table 2) become

$$
\mathrm{p}=\frac{-1+\epsilon_{\mathrm{o}}^{(2)} \mathrm{K}_{\mathrm{R}}}{\tau_{\mathrm{R}}}=\frac{-1+(0.75)(1.73)}{0.47}=0.63
$$

and

$$
\mathrm{z}=\frac{-1+\epsilon_{1} \mathrm{~K}_{\mathrm{R}}}{\tau_{\mathrm{R}}}=\frac{-1+(0.73)(1.73)}{0.47}=0.56
$$

For configuration $A$, we have $p=0.63$ and $z=0.56$, and for configuration $B$, the pole and zero are $p=0.26$ and $z=-0.10$, respectively. It then becomes clear that recovering the steam at a higher temperature is al ways favorable and the advantage comes from considerations of stability as well as possible RHP zeroes. In other
Table 3. Process Stream Data for Figure 10 (Case A)

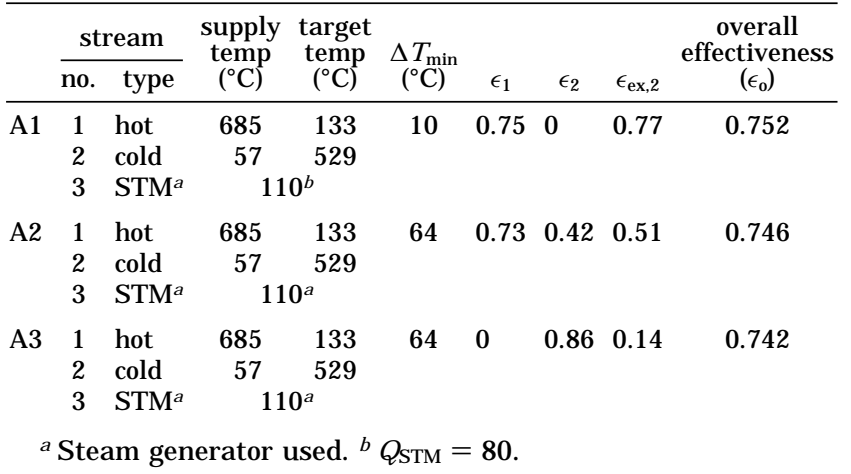

words, any configuration that gives delayed positive feedback is always favorable.

Again, the $\mathrm{T}-\mathrm{H}$ diagram can identity favorable configurations. As shown in Figure $7 \mathrm{C}$, the $\mathrm{T}-\mathrm{H}$ diagram in the far right of Figure $7 C$ is dynamically favorable.

3.4. Heuristics. Several observations can be made from the preceding analyses:

(1) I ntegrate heat back to the positive feedback loop. If a larger amount of heat is recovered via the FEHE, $\epsilon_{\mathrm{o}}$ is larger, which implies that the system is dynamically less favorable (case A3 in Table 2 and Figure 7A).

(2) Integrate heat away from the positive feedback loop. If heat is recovered via a steam generator (i.e., nonzero $\left.\epsilon_{\mathrm{ex}, \mathrm{i}}\right)$, then $\epsilon_{\mathrm{o}}$ is smaller, which means that the configuration is dynamically favorable (cases B2 and B3 in Table 2 and Figure 7B).

(3) Integrate the heat immediately away from the positive feedback loop. If the temperature level of the steam generator is closed to $T_{\text {out }}$, then $\epsilon_{1}$ is small (and $\epsilon_{2}$ is relative large), which implies that the system is dynamically favorable (from the considerations of stability and possible RHP zeroes).

Because $\mathrm{T}-\mathrm{H}$ diagrams are often used in the design of heat-integrated systems, the dynamically favorable configurations can also be identified, as shown in Figure 7.

These observations facilitate the assessment of the inherent controllability of any given design on the basis of the $\mathrm{T}-\mathrm{H}$ diagrams (Figure 7 ) or process flowsheets (Figures 6, 8, and 9)

3.5. Simple Example. In the design phase, it is always hel pful to reduce the number of heat exchangers, and the same principle applies to feed-effluent heat exchangers.${ }^{15}$ Here, we are interested in how this affects the overall effectiveness. The original flowsheet is a system with two FEHEs, as shown in the center flowsheet of Figure 10A; Figure 10B gives the corresponding $\mathrm{T}-\mathrm{H}$ diagram, where the horizontal line represents the reboiler of a distillation column. Two alternatives exist for reducing the number of FEHEs. One is to move the reboiler to the effluent of the reactor, as shown in the right flowsheet of Figure 10A, which results in the horizontal line being shifted to the right (Figure 10B). Figure 10C shows that the overall effectiveness decreases (Table 3 gives the numerical values), because the heat was integrated away immediately. The second alternative moves the reboiler outside the positive feedback loop, as shown in the left flowsheet of Figure 10A. This leads to a larger value of $\epsilon_{\mathrm{o}}$ (case A1 of Table 3). 
(A) Flowsheet
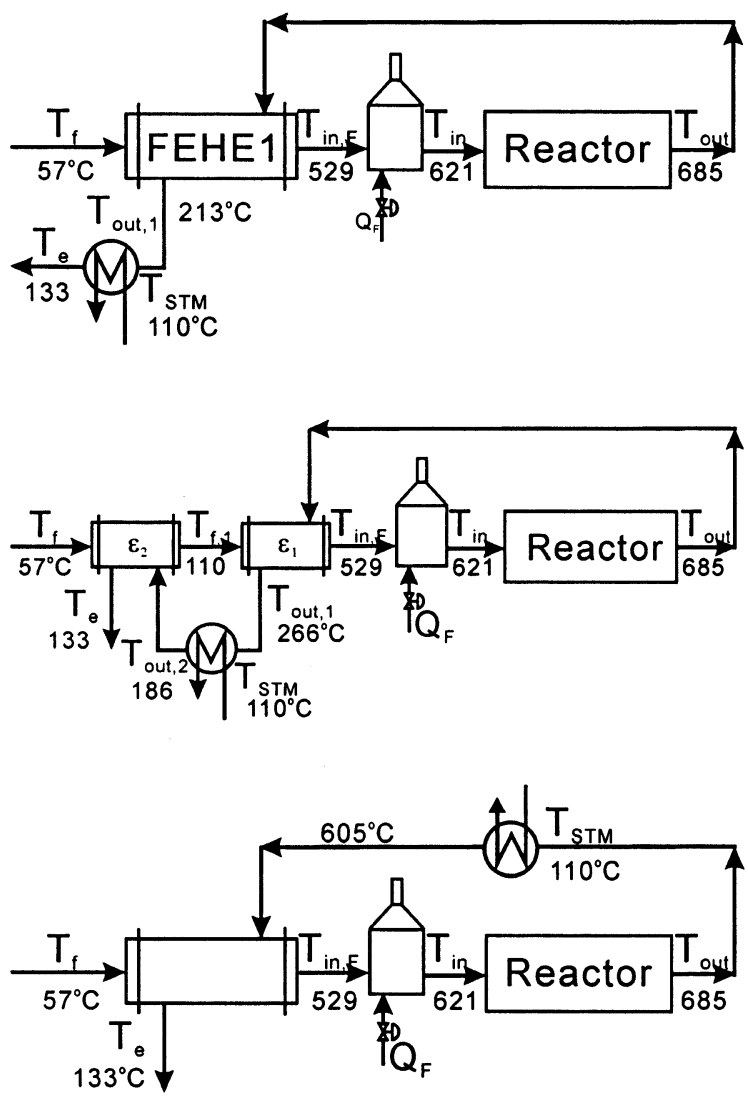

(B) $\mathrm{T}-\mathrm{H}$ diagram

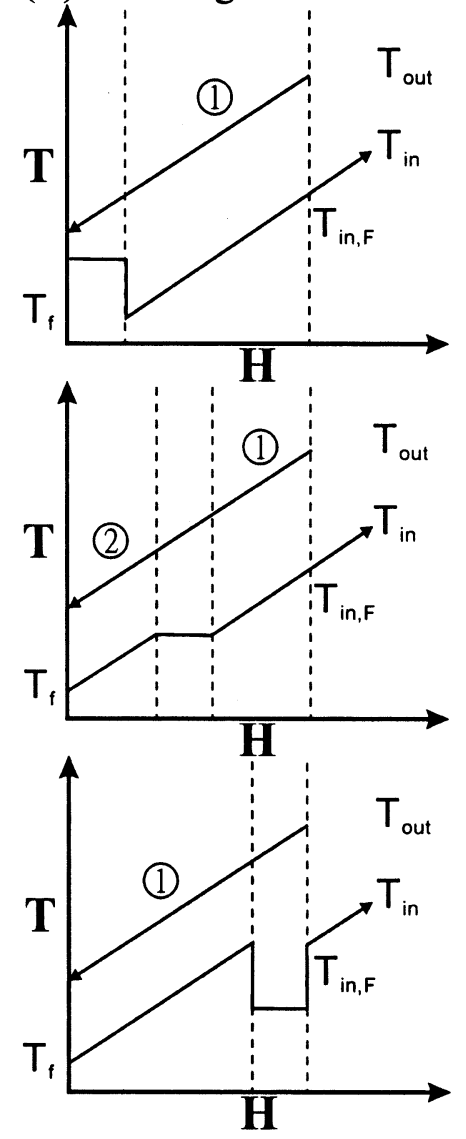

(C) Overall Effectiveness

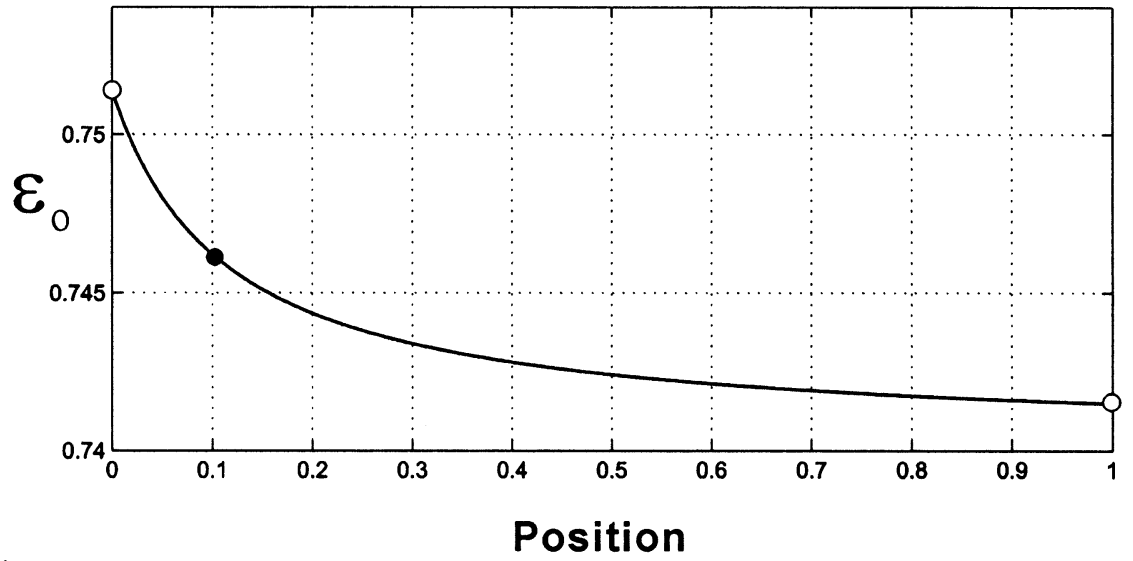

(D) Total Area

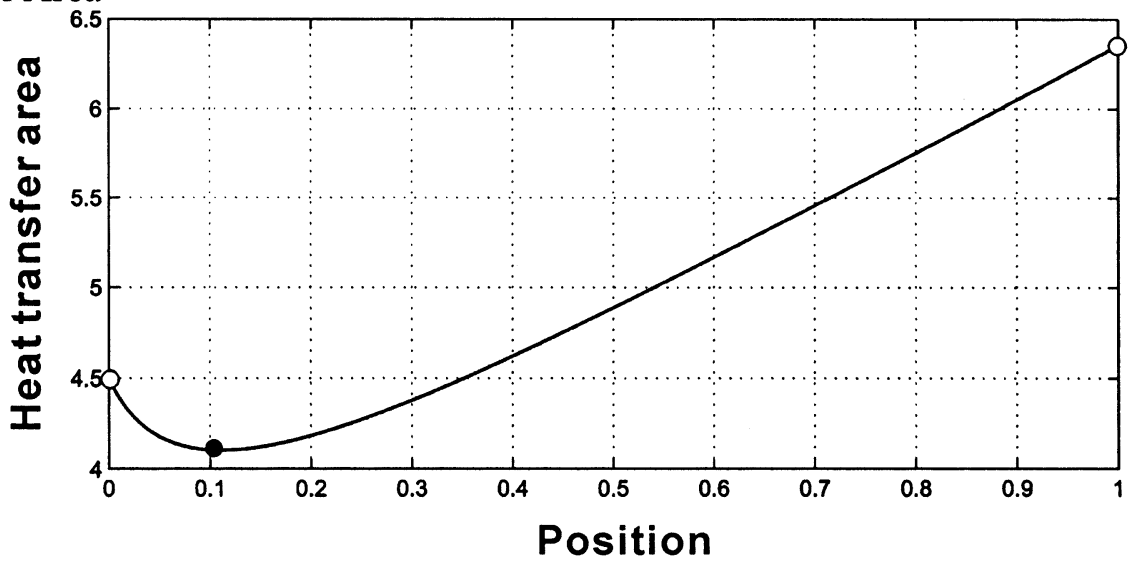

Figure 10. Steady-state design effect on overall effectiveness. 
(A)

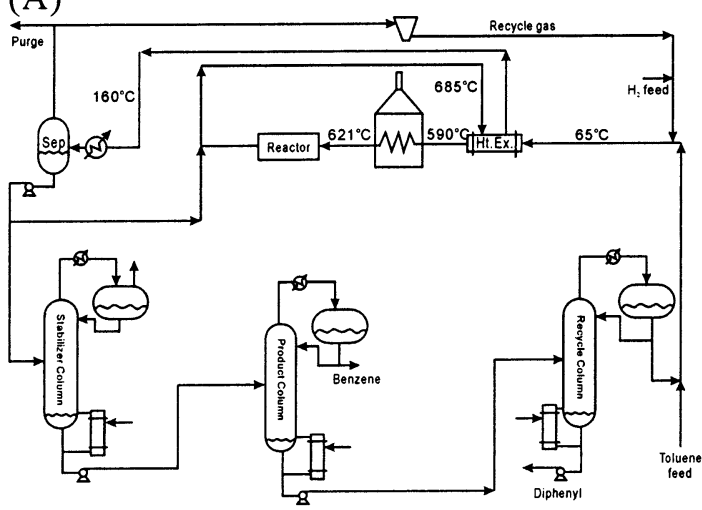

(C)

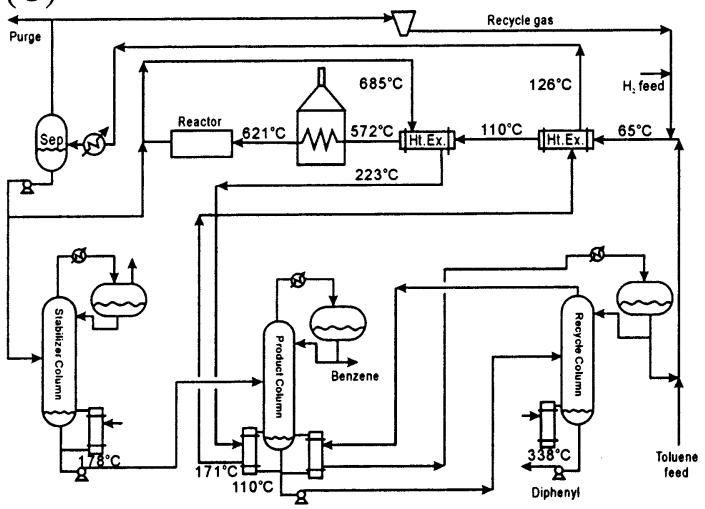

(E)

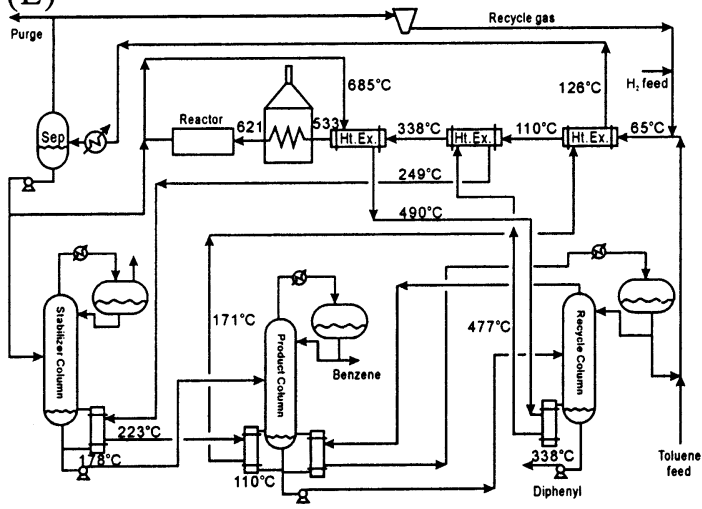

(B)

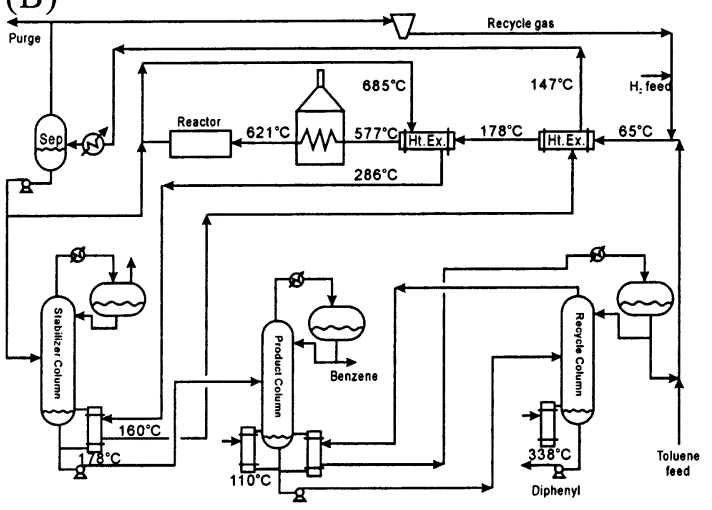

(D)

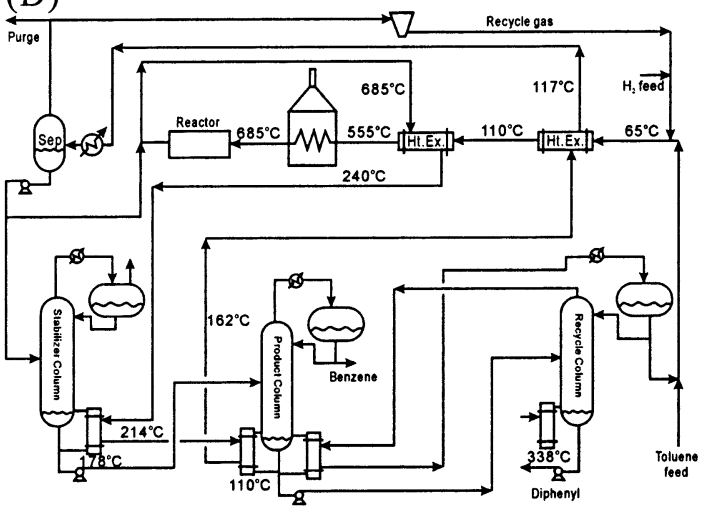

Figure 11. HDA alternative structures: (A) alternative 1, (B) alternative 3, (C) alternative 4, (D) alternative 5, (E) alternative 6.

The results indicate that, if the reboilers are moved closer to the reactor effluent, the positive feedback system becomes more controllable. However, Figure 10D reveals that, if such a change is made, then a much larger total heat-transfer area is required, and the tradeoff between steady-state economics and dynamic controllability becomes evident. In this example, the marginal improvement in the overall effectiveness does not justify the shift of the reboiler position toward the reactor.

\section{Steady-State Design I llustration}

4.1. HDA Example. In a series of papers, Terrill and Douglas ${ }^{15-17}$ used temperature-enthalpy diagrams to synthesize heat exchanger networks for the HDA process (Figure 11). The total annual costs (TACs) for six design alternatives are compared in ref 16 , and the steady-state operability is evaluated in terms of the ranges of manipulated variables. ${ }^{17}$ Terrill and Douglas ${ }^{16}$ also show that, compared with the base case, the energy savings range from $29 \%$ (alternative 1 ) to $43 \%$ (alternative 6), with a saving in TAC of $5 \%$ for al ternative 6 . Luyben et al. ${ }^{9}$ analyzed the heat pathway for the HDA plant and proposed control schemes for one of the more complex flowsheets, namely, alternative 6 (Figure 11E).

As pointed out earlier, the inherent dynamics of these heat-integration alternatives can be evaluated on the basis of the steady-state design data, and the open-loop pole of the positive feedback loop can be identified once the reactor dynamics is available.

Consider the $\mathrm{T}-\mathrm{H}$ diagram for an HDA process alternative such as that presented for alternative 7 in the flowsheet in Figure 12A.9,15 The hot stream starts from the reactor effluent $\left(685^{\circ} \mathrm{C}\right)$ and ends at the outl et of the last FEHE $\left(130^{\circ} \mathrm{C}\right)$. The cold stream starts from the inlet to the FEHE $\left(65^{\circ} \mathrm{C}\right)$ and ends at the reactor inlet $\left(529^{\circ} \mathrm{C}\right)$. The horizontal lines correspond to the reboilers for the recycle column, stabilizer, and product 
(A)

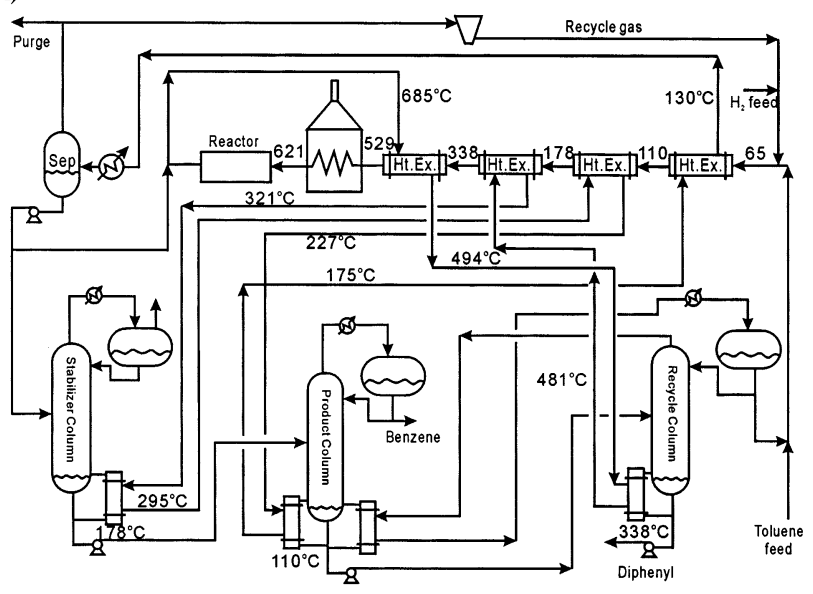

(B)

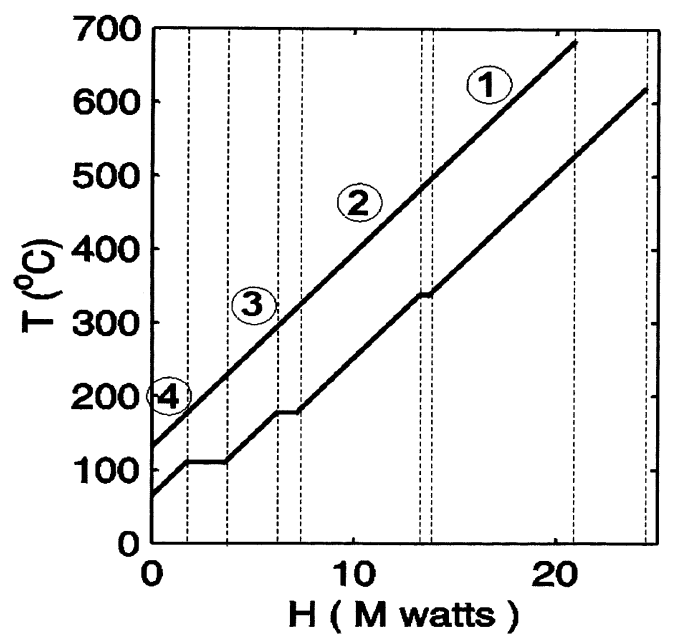

Figure 12. HDA alternative structure 7: (A) flowsheet, (B) $\mathrm{T}-\mathrm{H}$ diagram.

column. In the T-H diagram (Figure 12B), we associate a heat exchanger with each of the intervals between the break lines except for the one on the far right, which corresponds to a furnace. The circled numbers in F igure 12B stand for the feed-effluent heat exchangers numbered from the outlet of the reactor toward the inlet stream. This base case is the completely heat-integrated system and is hereafter denoted as al ternative 7 . This is a very complex heat-integration scheme with four FEHEs, and more importantly, the positive energy feedback to the highly exothermic reactor can result in an open-loop unstable system.

One way to reduce the complexity is to decrease the number of exchangers. We can shift the stabilizer reboiler so that the outlet of the second FEHE drives the stabilizer and, consequently, the product column. (In this way, we can eliminate the third FEHE, as shown in the $\mathrm{T}-\mathrm{H}$ diagram denoted as alternative 6 (Figure 13E). If we use the utility to drive the recycle column reboiler, another FEHE can be eliminated, as shown in the $\mathrm{T}-\mathrm{H}$ diagram of Figure 13D (alternative 5). Also note that, in alternative 5, there are still two FEHEs and the first FEHE is much larger than the second one. Further modifications are to drive the stabilizer reboiler with the utility (alternative 4) or to drive the product column reboiler with the utility (alternative 3) as shown in Figure $13 \mathrm{C}$ and $\mathrm{B}$, respectively. As for alternative 5, these two alternatives al so have two F E HEs with a relatively large exchanger right
(A)
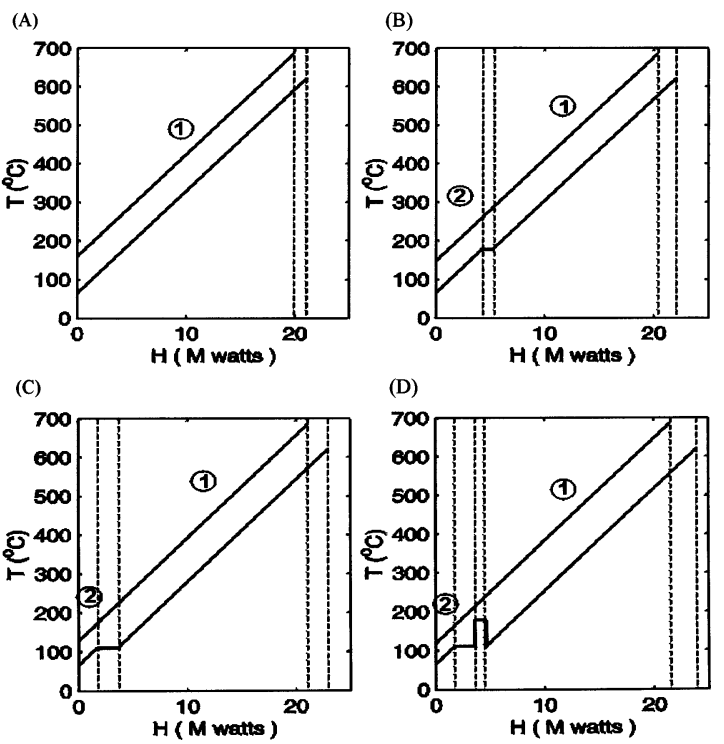

(E)

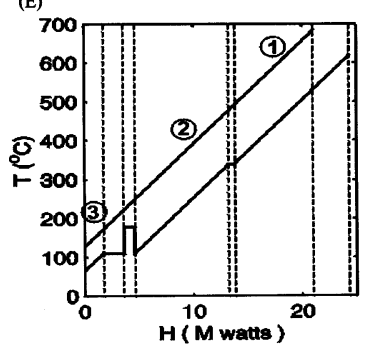

Figure 13. $\mathrm{T}-\mathrm{H}$ diagram for HDA alternative structures: (A) alternative $1,(B)$ alternative $3,(C)$ alternative 4 , (D) alternative 5, (E) alternative 6.

after the reactor effluent. Yet another alternative is to heat all three reboilers with the utility, which leaves only one FE HE , corresponding to alternative 1 (F igures $11 \mathrm{~A}$ and 13A). Actually, alternative 1 is the original HDA process (without heat integration to distillation columns) of Terrill and Douglas ${ }^{16}$ and Luyben et al. ${ }^{9}$

The next question then becomes: Which of these alternatives are dynamically favorable? Certainly, the overall effectiveness provides a quantitative measure. Before getting into computation details, note that the following assumption is made: the capacity flow rates of the hot stream $\left(C_{p, H}\right)$ and the cold stream $\left(C_{p, C}\right)$ are the same, i.e., $C_{p, H}=C_{p, C}=0.0378 \mathrm{MW}^{\circ} \mathrm{C}^{-1}$.

The effectiveness of each exchanger and reboiler can be calculated according to eqs 1 and A8, respectively. We consider alternative 6 here to illustrate the procedure. From the inlet and outlet temperatures, the effectiveness factor of the first FEHE $\left(\epsilon_{1}\right)$ can be obtained as

$$
\epsilon_{1}=\frac{533-338}{685-338}=0.56
$$

Given the boilup temperature, the effectiveness of the recycle column reboiler $\left(\epsilon_{\mathrm{ex}, 2}\right)$ can also be calculated as

$$
\epsilon_{\mathrm{ex}, 2}=\frac{490-477}{490-338}=0.09
$$

We can repeat the same procedure for all three FEHEs and both of the steam generators. Table 4 lists the numerical values for all these effectiveness factors. The 
2802 Ind. Eng. Chem. Res., Vol. 42, No. 12, 2003

Table 4. Effectiveness Factors of Heat Exchangers and Reboilers for HDA Alternatives

\begin{tabular}{ccccccccccccccccc}
\hline alternative & $\epsilon_{1}$ & $\epsilon_{\mathrm{ex}, 1}$ & $\epsilon_{2}$ & $\epsilon_{\mathrm{ex}, 2,1}$ & $\epsilon_{\mathrm{ex}, 2,2}$ & $\epsilon_{3}$ & $\epsilon_{\mathrm{ex}, 3,1}$ & $\epsilon_{\mathrm{ex}, 3,2}$ & $\epsilon_{4}$ & $\epsilon_{\mathrm{ex} 4}$ & $\epsilon_{\mathrm{o}}$ & $\begin{array}{c}\mathrm{Q}_{\mathrm{FEHE}} \\
(\mathrm{MW})\end{array}$ & $\begin{array}{c}\mathrm{Q}_{\mathrm{REB}} \\
(\mathrm{MW})\end{array}$ & $\begin{array}{c}\mathrm{Q}_{\mathrm{F}} \\
(\mathrm{MW})\end{array}$ & $\begin{array}{c}\mathrm{Q}_{\mathrm{REC}}{ }^{\mathrm{a}} \\
(\mathrm{MW})\end{array}$ & $\begin{array}{c}\mathrm{Q}_{\mathrm{HU}} \mathrm{b} \\
(\mathrm{MW})\end{array}$ \\
\hline 1 & 0.85 & 0 & 0 & 0 & 0 & 0 & 0 & 0 & 0 & 0 & 0.850 & 19.9 & 0.0 & 1.2 & 19.9 & 4.6 \\
3 & 0.79 & 0 & 0.58 & 0.24 & 0 & 0 & 0 & 0 & 0 & 0 & 0.820 & 19.4 & 1.0 & 1.7 & 20.3 & 4.1 \\
4 & 0.80 & 0 & 0.34 & 0.23 & 0 & 0 & 0 & 0 & 0 & 0 & 0.816 & 19.2 & 1.9 & 1.9 & 21.1 & 3.3 \\
5 & 0.77 & 0 & 0.46 & 0.42 & 0.49 & 0 & 0 & 0 & 0 & 0 & 0.778 & 18.5 & 2.9 & 2.5 & 21.4 & 3.0 \\
6 & 0.56 & 0 & 0.62 & 0.09 & 0 & 0.42 & 0.37 & 0.45 & 0 & 0 & 0.729 & 17.7 & 3.4 & 3.3 & 21.1 & 3.3 \\
7 & 0.55 & 0 & 0.53 & 0.08 & 0 & 0.37 & 0.18 & 0 & 0.41 & 0.44 & 0.725 & 17.6 & 3.4 & 3.5 & 21.0 & 3.5
\end{tabular}

${ }^{a}$ Energy required for FEHE and distillation reboiler $\left(Q_{F E H E}=Q_{R E B}+Q_{R E C}\right){ }^{b}$ Hot utility usage for process $\left(Q_{H U}=Q_{F}+Q_{R E B}, \max -\right.$ QREB $)$.

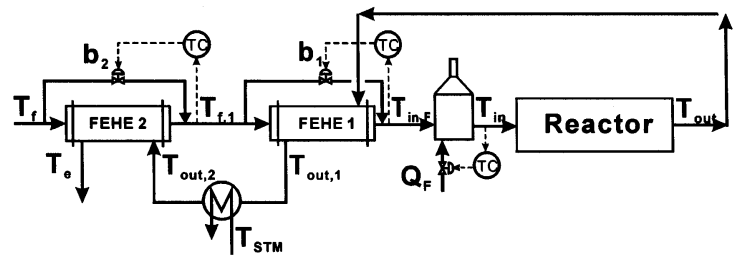

Figure 14. FEHE/reactor system with two feed-effluent heat exchangers and three temperature control loops.

overall effectiveness can then be computed using Table 1

$$
\begin{gathered}
\epsilon_{\mathrm{o}}^{(3)}=\left[\epsilon_{1}\left(1-\epsilon_{\mathrm{ex}, 1}\right)+\epsilon_{2}\left(1-\epsilon_{\mathrm{ex}, 2}\right)\left(1-2 \epsilon_{1}\right)(1-\right. \\
\left.\epsilon_{\mathrm{ex}, 1}\right)+\epsilon_{3}\left(1-\epsilon_{\mathrm{ex}, 3}\right)\left(1-\epsilon_{\mathrm{ex}, 2}\right)\left(1-\epsilon_{\mathrm{ex}, 1}\right)\left(1-2 \epsilon_{2}\right)(1- \\
\left.\left.2 \epsilon_{1}\right)-\epsilon_{1} \epsilon_{2} \epsilon_{3}\left(1-\epsilon_{\mathrm{ex}, 3}\right)\left(1-\epsilon_{\mathrm{ex}, 1}\right)\right] /\left[1-\epsilon_{1} \epsilon_{2}\left(1-\epsilon_{\mathrm{ex}, 2}\right)-\right. \\
\left.\epsilon_{1} \epsilon_{3}\left(1-\epsilon_{\mathrm{ex}, 3}\right)\left(1-\epsilon_{\mathrm{ex}, 2}\right)\left(1-2 \epsilon_{2}\right)-\epsilon_{2} \epsilon_{3}\left(1-\epsilon_{\mathrm{ex}, 3}\right)\right] \\
=\{0.56(1-0)+0.62(1-0.09)[1-2(0.56)](1- \\
0)+0.42(1-0.37)(1-0.45)(1-0.09)[1- \\
2(0.62)][1-2(0.56)]-(0.56)(0.62)(0.42)(1- \\
0.37)(1-0.45)(1-0)\} /\{1-(0.56)(0.62)(1- \\
0.09)-(0.56)(0.42)(1-0.37)(1-0.45)(1- \\
0.09)[1-2(0.62)]-(0.62)(0.42)(1- \\
0.37)(1-0.45)\} \\
=0.73
\end{gathered}
$$

The $\epsilon_{\mathrm{o}}$ values for all six alternatives can be obtained similarly, giving the results reported in Table 4.

\section{Control System Analysis}

Figure 14 shows two FEHEs coupled with an adiabatic exothermic reactor. The heat of the reaction produces a reactor effluent temperature ( $\left.T_{\text {out }}\right)$ that is higher than the temperature of the feed stream $\left(T_{f}\right)$. Therefore, heat can be recovered from the hot stream. The heat is utilized to heat the feed stream and to provide the heat input to a steam generator at a temperature of $\mathrm{T}_{\mathrm{b} 1}$. Typically, a furnace is al so required for the startup of these systems, as shown in Figure 14. The control objective is to maintain the reactor inlet temperature $\left(T_{\text {in }}\right)$.

5.1. Manipulated Control Variables. There are three candidate manipulated variables for this dual$\mathrm{FEHE} /$ reactor system. Because the startup furnace is available, the furnace temperature could be used as a manipulated variable. The other two manipulated inputs come from the bypass flows of the two FEHEs. Note that mixing of the heated and bypass streams provides an immediate change in the outlet temperature $\left(T_{\text {in, }} \mathrm{F}\right.$ or $\left.T_{f, 1}\right)$, and fast dynamics can be expected. These two bypasses $\left(b_{1}\right.$ and $\left.b_{2}\right)$ provide two additional manipulated variables. Also note that, to provide an additional

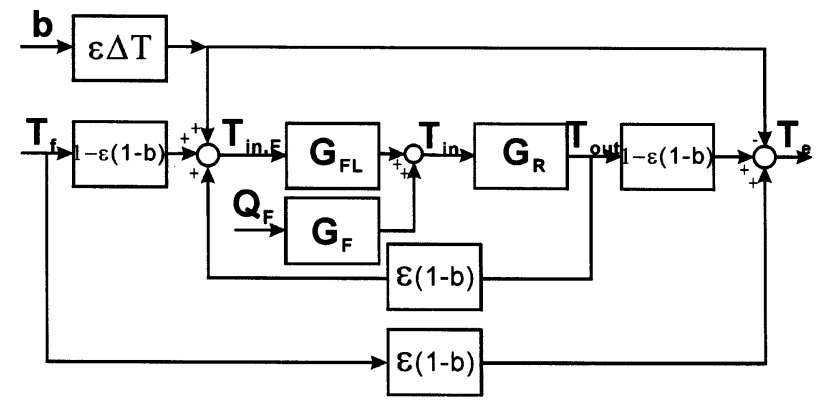

Figure 15. Block diagram for the simple FEHE/reactor system with a heat exchanger bypass (b).

manipulated variable, the area of the bypass heat exchanger is larger than that of the heat exchanger without the bypass. In terms of effectiveness, it can be shown that

$$
\epsilon_{\mathrm{wo}}=\epsilon_{\mathrm{w}}(1-\mathrm{b})
$$

where $\epsilon$ is the effectiveness; the subscripts wo and w denote without and with, respectively; and b represents the bypass ratio.

Given three manipulated inputs, the controlled variables are the exit temperatures of the heat exchangers and furnace $\left(T_{f, 1}, T_{i n, F}\right.$, and $\left.T_{i n}\right)$. If all three temperatures are controlled, intuitively, the pairing should be $\mathrm{T}_{\text {in }}-$ $Q_{F}, T_{i n, F}-b_{1}$, and $T_{f, 1}-b_{2}$ because of the preference of fast dynamics between manipulated and controlled variables. Figure 14 shows the cases in which one, two, and three temperatures are controlled.

5.2. Process Transfer F unctions. Similarly to the overall effectiveness $\left(\epsilon_{o}^{(i)}\right)$, the multivariable process transfer functions can also be derived systematically, provided that the reactor, furnace, and heat exchanger dynamics are known. Because a furnace and a bypass are added to the system to provide candidate manipulated variables, the block diagram differs from that of the design phase (i.e., Figure 3). A simpleFEHE/reactor system, shown in Figure 15 is used to illustrate the derivation. The effect of the bypass ratio $b$ on the inlet temperature to the furnace $\left(T_{i n, F}\right)$ and the exit temperature of the hot stream $T_{e}$ can be derived as

$$
\mathbf{T}_{\mathrm{in}, \mathrm{F}}=[1-\epsilon(1-\overline{\mathrm{b}})] \mathrm{T}_{\mathrm{f}}+\epsilon(1-\overline{\mathrm{b}}) \mathrm{T}_{\text {out }}
$$

Linearization of eq 42 gives the steady-state gain between $b$ and $T_{i n, F}$ and $T_{e}$ (Figure 15). Figure 15 al so shows that two transfer functions aare ssociated with the furnace. One is the load-transfer function describing the relationship between $T_{i n, F}$ and $T_{\text {in }}\left(G_{F L}\right)$, which, generally, has a gain close to unity. The second is the transfer function $\left(G_{F}\right)$ relates the fuel flow $\left(Q_{F}\right)$ to the inlet temperature of the reactor $\left(T_{\text {in }}\right)$. With the slightly 


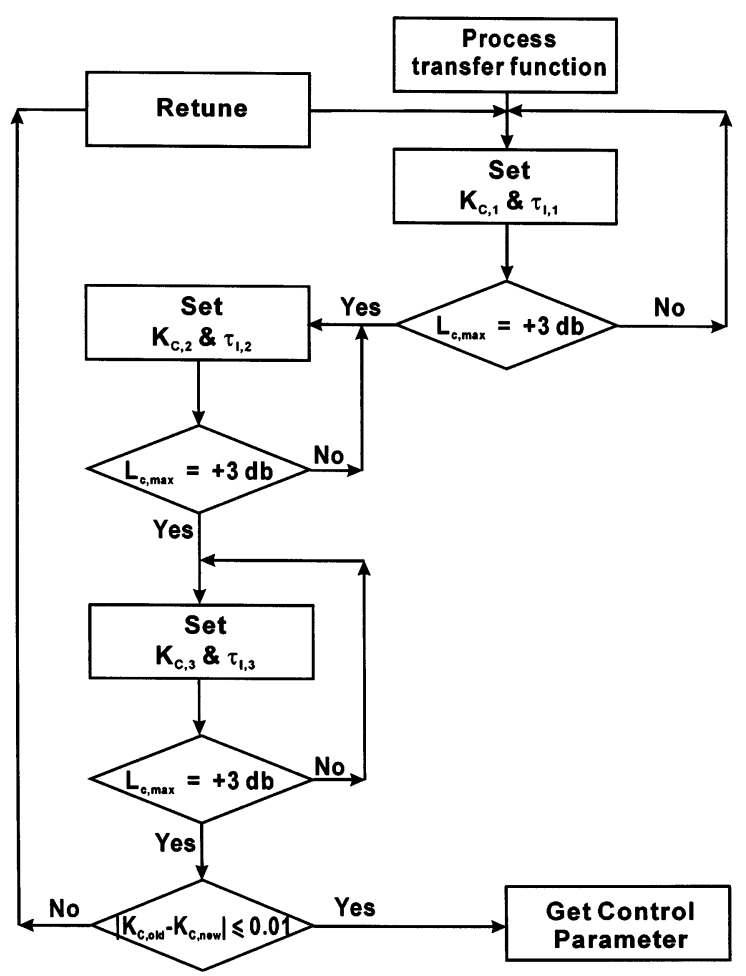

Figure 16. Sequential tuning procedure with $a+3-d b$ criterion.

modified block diagram in Figure 15 (compared to Figure 3), we can derive the process transfer function.

For the simple process, we have two possible controlled variables, $T_{\text {in }}$ and $T_{i n, F}$, and two manipulated inputs, $Q_{F}$ and $b$. The relationship between $T_{\text {in }}$ and $Q_{F}$ can be derived directly from the block diagram

$$
\left[\begin{array}{l}
T_{i n}(s) \\
T_{i n, F}(s)
\end{array}\right]=\left[\begin{array}{ll}
g_{11} & g_{12} \\
g_{21} & g_{22}
\end{array}\right]\left[\begin{array}{l}
Q_{F}(s) \\
b(s)
\end{array}\right]+\left[\begin{array}{l}
g_{d 1} \\
g_{d 2}
\end{array}\right] T_{f}(s)
$$

where

$$
\begin{aligned}
& g_{11}=\frac{G_{F}}{1-K_{\mathrm{FL}} \epsilon(1-\bar{b}) G_{\mathrm{R}}}, \quad g_{12}=\frac{\mathrm{K}_{\mathrm{FL}} \epsilon \Delta \overline{\mathrm{T}}}{1-\mathrm{K}_{\mathrm{FL}} \epsilon(1-\overline{\mathrm{b}}) \mathrm{G}_{\mathrm{R}}} \\
& \mathrm{g}_{21}=\frac{\mathrm{G}_{\mathrm{F}} \mathrm{G}_{\mathrm{R}} \epsilon(1-\overline{\mathrm{b}})}{1-\mathrm{K}_{\mathrm{FL}} \epsilon(1-\overline{\mathrm{b}}) \mathrm{G}_{\mathrm{R}}}, \quad g_{22}=\frac{\epsilon \Delta \overline{\mathrm{T}}}{1-\mathrm{K}_{\mathrm{FL}} \epsilon(1-\overline{\mathrm{b}}) \mathrm{G}_{\mathrm{R}}} \\
& \mathrm{g}_{\mathrm{d} 1}=\frac{[1-\epsilon(1-\overline{\mathrm{b}})] \mathrm{K}_{\mathrm{FL}}}{1-\mathrm{K}_{\mathrm{FL}} \epsilon(1-\overline{\mathrm{b}}) \mathrm{G}_{\mathrm{R}}}, \quad g_{\mathrm{d} 2}=\frac{1-\epsilon(1-\overline{\mathrm{b}})}{1-\mathrm{K}_{\mathrm{FL}} \epsilon(1-\overline{\mathrm{b}}) \mathrm{G}_{\mathrm{R}}}
\end{aligned}
$$

This approach can be extended directly to a more complex scheme. Once the transfer functions become available, one can analyze the fault tolerance and disturbance rejection aspects of compl ex FEHE/reactor schemes.

5.3. Analysis. For comparison, PI controllers were used for three different control structures (Figure 14). A sequential tuning approach was used here, ${ }^{12}$ along with a +3-db maximum in the logarithm of the closedloop modulus $\left(L_{c, \max }=3 \mathrm{db}\right.$ ). Similarly to the $B L T$ tuning method, ${ }^{5}$ the detuning factors, $\mathrm{f}_{\mathrm{i}}$, were adjusted such that the value of $L_{c \text {,max }}$ in each loop reached $+3 \mathrm{db}$ (when the other loops were closed). Figure 16 describes the sequential tuning procedure.

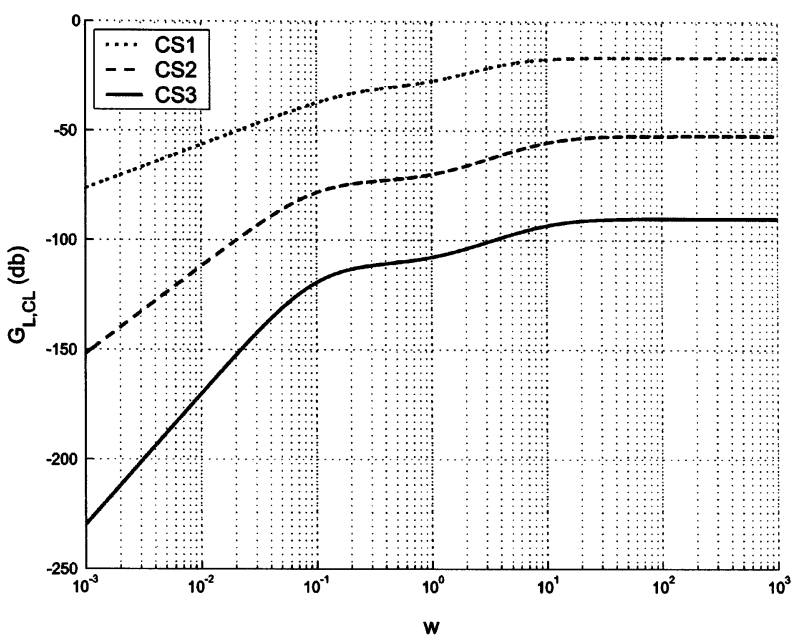

Figure 17. Closed-loop load-transfer function between $T_{\text {in }}$ and $\mathrm{T}_{\mathrm{f}}$ with different control structures: control structure 1 (CS1; one temperature loop, $Q_{F}-T_{\text {in }}$ ), control structure 2 (CS2; two temperature loops, $Q_{F}-T_{\text {in }}$ and $b_{1}-T_{i n, F}$ ), control structure 3 (CS3; three temperature loops, $Q_{F}-T_{i n}, b_{1}-T_{i n, F}$, and $b_{2}-T_{f 1}$ ). (Note that temperature measurement lags are not included in computing frequency responses.)

5.3.1. Disturbance Rejection. Three different control structures are compared here. These three structures correspond to $1 \times 1,2 \times 2$, and $3 \times 3$ systems (i.e., control of one, two, and three temperatures, respectively, in Figure 14). The process transfer functions are simply the principal submatrices of eq 43. Here, we are interested in the closed-loop load-transfer function $\left(G_{L, C L}\right)$ with the corresponding controllers present.

When PI controllers are used, each $\mathrm{S}_{i}$ has a slope of $+20 \mathrm{db} /$ decade in the loop frequency asymptote. In the case when three temperatures are controlled, this results in a slope of $+60 \mathrm{db} /$ decade in the low-frequency range, compared to $+20 \mathrm{db} /$ decade when only $T_{\text {in }}$ is controlled (see Appendix C for the derivation). This means that, in the low-frequency range, good control of $\mathrm{T}_{\text {in }}$ can be achieved if more heat exchanger exit temperatures $\left(T_{i n, F}\right.$ and/or $\left.T_{f, 1}\right)$ are controlled. In terms of time-domain responses, Figure 17 illustrates that $T_{\text {in }}$ will return to the set point more quickly if additional temperatures, e.g., $T_{\mathrm{in}, \mathrm{F}}$ and/or $\mathrm{T}_{\mathrm{f}, 1}$, are controlled.

Next, the initial responses are analyzed. In the case of a simple FE HE/reactor system, Figure 15 shows that, if the furnace is used to control the reactor inlet temperature $\left(T_{\text {in }}\right)$, the high-frequency asymptote of the closed-loop load-transfer function becomes

$$
\mathrm{G}_{\mathrm{L}, \mathrm{CS} 1}(\infty)=1-\epsilon_{1}
$$

If both the furnace $\left(Q_{F}\right)$ and the bypass (b) are used, then $G_{L, C L}(\infty)$ can be derived from eq 43 , which gives, after some al gebraic manipulation

$$
\mathrm{G}_{\mathrm{L}, \mathrm{CS} 2}(\infty)=\frac{\left(1-\epsilon_{1}\right)}{1+\mathrm{K}_{2} \mathrm{~K}_{\mathrm{C} 2} \tau_{1,2}}
$$

Equation 45 clearly indicates that the additional temperature loop lowers the high-frequency asymptote and, thus, a better initial response is obtained. Similar results can be derived for more complex FEHE/reactor schemes. Given the closed-loop load-transfer functions for all three cases, the high-frequency asymptotes for 
one to three temperature loops are

$$
\begin{gathered}
\mathrm{G}_{\mathrm{L}, \mathrm{CS} 1}(\infty)=\frac{\left(1-\epsilon_{1}\right)\left(1-\epsilon_{2}\right)}{1-\epsilon_{1} \epsilon_{2}\left(1-\epsilon_{\mathrm{ex}, 2}\right)} \\
\mathrm{G}_{\mathrm{L}, \mathrm{CS} 2}(\infty)= \\
\frac{\left(1-\epsilon_{1}\right)\left(1-\epsilon_{2}\right)\left(1-\mathrm{K}_{\mathrm{b} 1} \mathrm{~K}_{\mathrm{C} 2}\right)}{\left(1+\mathrm{K}_{\mathrm{b} 1} \mathrm{~K}_{\mathrm{C} 2}\right)\left[1-\mathrm{K}_{\mathrm{b} 1} \mathrm{~K}_{\mathrm{C} 2}-\epsilon_{1} \epsilon_{2}\left(1-\epsilon_{\mathrm{ex}, 2}\right)\right]}(47) \\
\mathrm{G}_{\mathrm{L}, \mathrm{CS} 3}(\infty)= \\
\frac{\left(1-\epsilon_{1}\right)\left(1-\epsilon_{2}\right)\left(1-\mathrm{K}_{\mathrm{b} 1} \mathrm{~K}_{\mathrm{C} 2}\right)}{\left(1+\mathrm{K}_{\mathrm{b} 1} \mathrm{~K}_{\mathrm{C} 2}\right)\left[\left(1-\mathrm{K}_{\mathrm{b} 1} \mathrm{~K}_{\mathrm{C} 2}\right)\left(1+\mathrm{K}_{\mathrm{b} 2} \mathrm{~K}_{\mathrm{C} 3}\right)-\epsilon_{1} \epsilon_{2}\left(1-\epsilon_{\mathrm{ex}, 2}\right)\right]}
\end{gathered}
$$

respectively. These results show that better initial responses can be obtained if more temperature control loops are installed (Figure 17).

Frequency-domain analyses reveal that complex heatintegration schemes provide the opportunity for more manipulated inputs and, consequently, more temperature control loops. The additional temperature control loops improve the frequency responses in both the lowand high-frequency ranges. This implies that the reactor inlet temperature $\left(T_{\text {in }}\right)$ will return to the set point more quickly and also with a smaller initial peak if more temperature loops are added.

5.4. Dual FEHEs. Two examples are studied here. One is a system with two FEHEs integrated with a reactor, as shown in Figure 14. The other is the HDA example.

Two reactor dynamics are considered here. The reactor dynamics are taken from the examples of Tyrens and Luyben. ${ }^{18}$

5.4.1. Reactor with First-Order Dynamics. The reactor inlet and outlet temperatures are described by the following transfer function

$$
G_{R}=\frac{K_{R} e^{-D s}}{\tau_{R} S+1}
$$

The furnace dynamics is given by

$$
\mathrm{G}_{\mathrm{F}}=\frac{\mathrm{K}_{\mathrm{F}}}{\tau_{\mathrm{F}} \mathrm{S}+1}
$$

The system has an overall effectiveness of 0.778 , which gives an open-loop unstable system ( $\mathrm{GM}=0.51)$. A third-order lag with a time constant of $0.1 \mathrm{~min}$ is applied to all temperature measurements.

Three control structures were studied. CS1 controls only one temperature ( $\left.\mathrm{T}_{\mathrm{in}}\right)$; CS2 controls both $\mathrm{T}_{\text {in }}$ and $T_{i n, F}$; and CS3 controls all three temperatures, $T_{i n}, T_{i n, F}$, and $T_{f, 1}$ (Figure 14). As expected, when more temperatures are controlled, better disturbance rejection can be achieved, as shown in Figure 18A. The initial peak in $\mathrm{T}_{\text {in }}$ was reduced from 1.87 for CS1 to 0.59 with CS2 and further down to 0.46 using CS3. The load responses confirm the results from frequency-domain analyses. Smaller settling times are also observed for CS2 and CS3 compared to CS1. Figure 18B shows that better setpoint responses can be obtained if more than one temperature is controlled (e.g., CS2 and CS3).

5.4.2. Reactor with Wrong-Way Behavior. Because wrong-way behavior (inverse response) is often
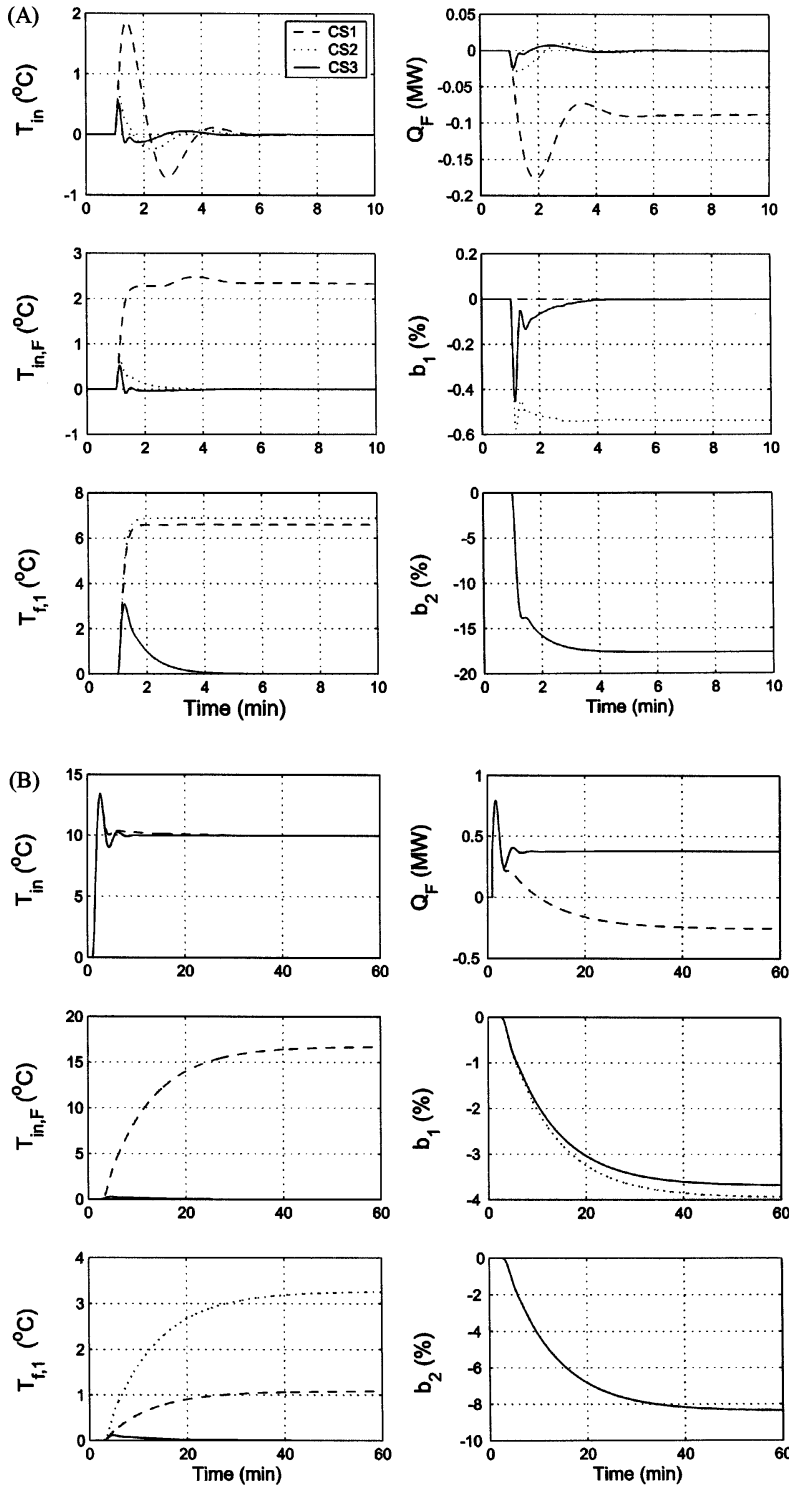

Figure 18. Closed-loop performances of CS1, CS2, and CS3 for a first-order plus dead time reactor dynamic under: (A) $+10^{\circ} \mathrm{C}$ feed temperature change, $(B)+10^{\circ} \mathrm{C}$ set-point change in $\mathrm{T}_{\mathrm{in}}$.

observed in the packed-bed reactor, the control performance of this type of reactor dynamics was al so studied. Consider an example of Tyreus and Luyben ${ }^{18}$

$$
\mathrm{G}_{\mathrm{R}}=\frac{\mathrm{K}_{\mathrm{R}}\left(-\tau_{2} \mathrm{~S}+1\right) \mathrm{e}^{-\mathrm{Ds}}}{\left(\tau_{1} \mathrm{~S}+1\right)^{2}}
$$

with furnace dynamics again given by eq 50 . The overall effectiveness is 0.782 , which gives an open-loop unstable system (i.e., $\epsilon_{0}{ }^{(1)} K_{R}>1$ ).

The load responses in Figure 19A show that, again, if more temperatures are controlled, better disturbance rejection can be achieved. This can be seen in the peak temperature (which decreases from 0.79 to 0.5 and then to $0.29{ }^{\circ} \mathrm{C}$ for $\mathrm{C} 1-\mathrm{C} 3$, respectively), as well as the settling time. CS2 and CS3 also give faster set-point responses, as shown in Figure 19B.

The dynamic response results presented in this section confirm the finding from the frequency-domain analysis. The complexity of the FEHE/reactor scheme leads to more candidates for manipulated inputs, and 

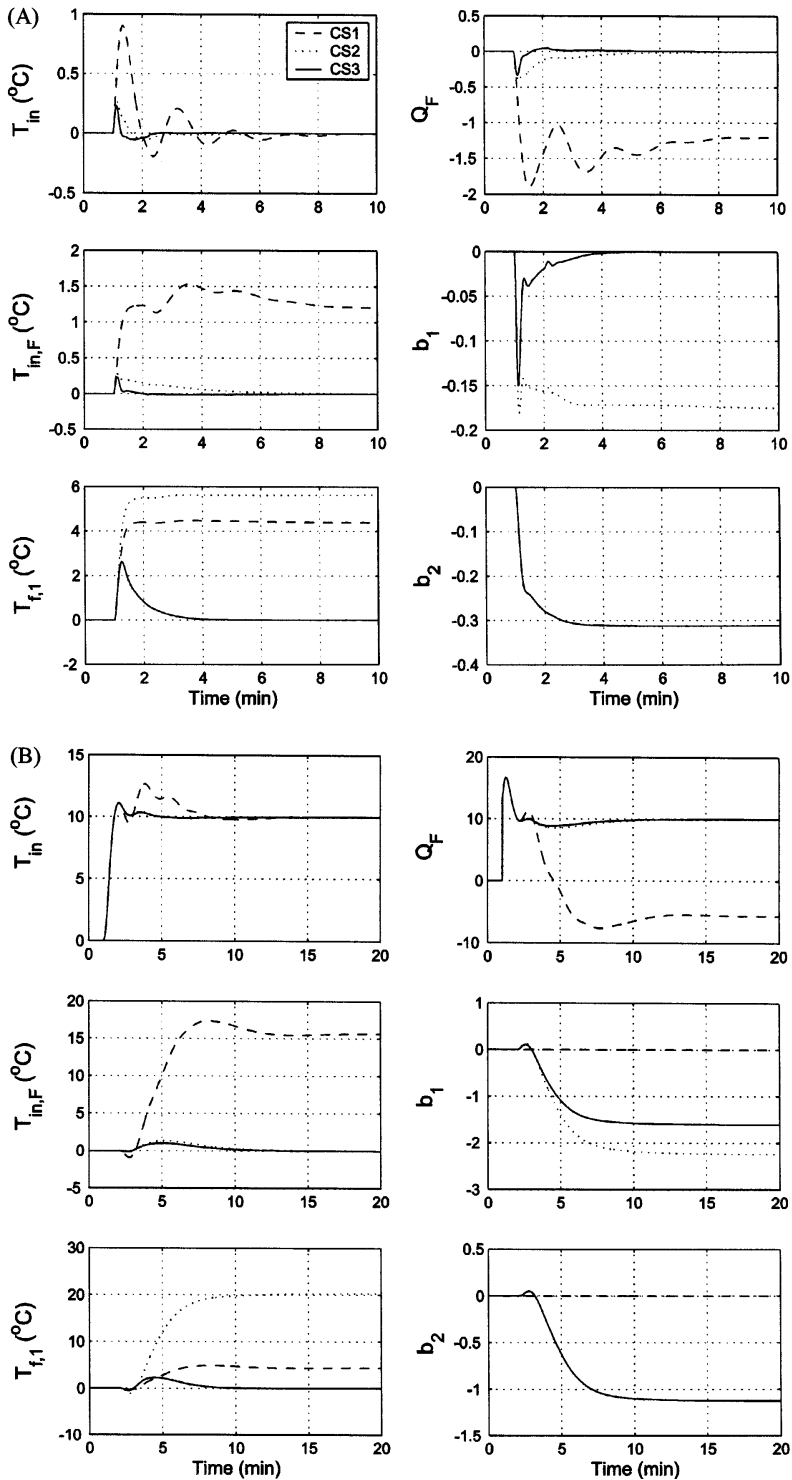

Figure 19. Closed-loop performances of CS1, CS2, and CS3 for wrong-way reactor dynamics under: $(\mathrm{A})+10^{\circ} \mathrm{C}$ feed temperature change, $(B)+10{ }^{\circ} \mathrm{C}$ set-point change in $\mathrm{T}_{\text {in }}$.

this results in better disturbance rejection while maintaining good robustness.

5.5. HDA Example. Alternatives 1 and 6 of the HDA flowsheets are studied here.9,15 The reactor geometry is taken from Luyben et al., ${ }^{9}$ and corresponds to a length of $57 \mathrm{ft}$ and a diameter of $9.53 \mathrm{ft}$ with a feed flow rate of $4382.5 \mathrm{lb} \cdot \mathrm{mol} / \mathrm{h}$. Two reactions take place in the reactor

$$
\begin{gathered}
\text { toluene }+\mathrm{H}_{2} \rightarrow \text { benzene }+\mathrm{CH}_{4} \\
\text { 2benzene } \leftrightarrow \text { diphenyl }+\mathrm{H}_{2}
\end{gathered}
$$

with the following reaction kinetics

$$
r_{1}=3.6858 \times 10^{6} \exp (-25616 / T) p_{T} p_{H}{ }^{1 / 2}
$$

The effectiveness factors of the heat exchangers and $r_{2}=5.987 \times 10^{4} \exp (-25616 / T) p_{H}{ }^{2}-2.553 \times$ $10^{5} \exp (-25616 / \mathrm{T}) \mathrm{p}_{\mathrm{D}} \mathrm{p}_{\mathrm{H}}$
(A) Alternative 1

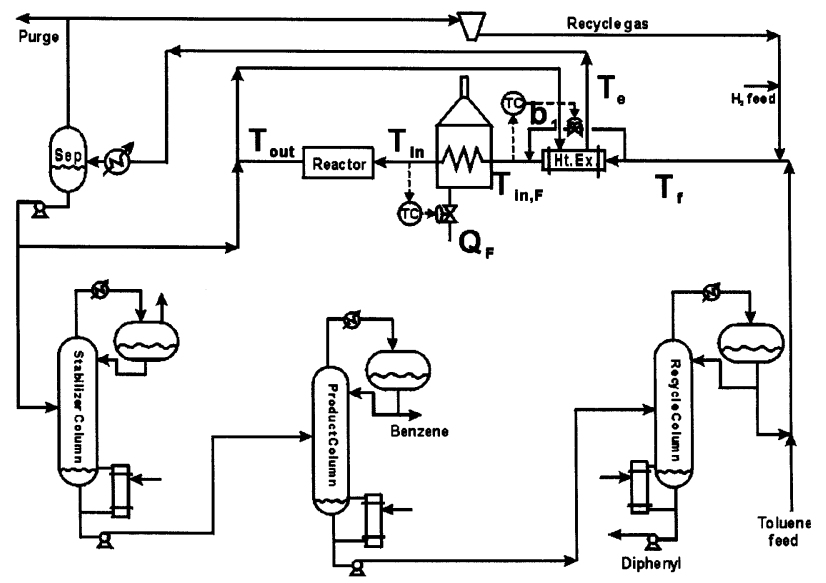

(B) Alternative 6

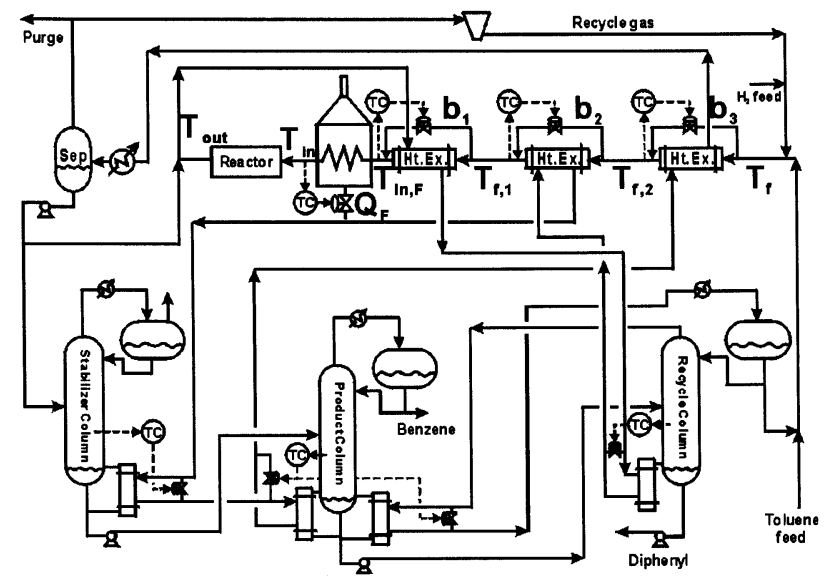

Figure 20. Control structures for HDA design alternatives.

corresponding temperatures are reported in Table 5 (and shown in Figure 20). In nonlinear simulations, 10 lumps were used to model the distributed parameter system. The heat exchanger dynamics were assumed to be instantaneous. At nominal steady-state, the linearized reactor model becomes

$$
\mathrm{G}_{\mathrm{R}}(\mathrm{s})=\frac{\mathrm{T}_{\text {out }}(\mathrm{s})}{\mathrm{T}_{\text {in }}(\mathrm{s})}=\frac{2.5}{1.3 \mathrm{~s}+1} \mathrm{e}^{-0.5 \mathrm{~s}}
$$

Also, recall that overall effectiveness factors for alternatives 1 and 6 are 0.85 and 0.73 , respectively. Both heat-integrated schemes are open-loop unstable, and the GM values are 0.47 and 0.55 , respectively. Two temperature control loops are used in alternative 1, and four temperature control loops are used in alternative 6 , as shown in Figure 20. Following the sequential tuning procedure (Figure 16), the tuning constants for alternatives 1 and 6 are listed in Table 6. Figure 21 shows the closed-loop load-transfer functions $\left(\mathrm{G}_{\mathrm{L}, \mathrm{CL}}\right)$ for both schemes. As pointed out earlier, the slopes of the low-frequency asymptotes are +20 and $+80 \mathrm{db} /$ decade for alternatives 1 and 6 , respectively. Alternative 6 al so gives better high-frequency responses. (Because measurement lags are added to the temperature measurement, the magnitudes approach zero at high frequency.) The frequency responses for the HDA process are consistent with our earlier findings in which better disturbance rejection can be expected for alternative 6 .

Time-domain simulations (Figure 22) reveal that much better load rejection is obtained using the more 
Table 5. Steady-State Process Data for FEHE/Reactor Systems with Dual FEHEs ${ }^{18}$ and Dynamic Parameters ${ }^{a}$

\begin{tabular}{|c|c|c|c|c|c|c|c|c|c|c|c|c|c|}
\hline reactor dynamics & $\epsilon_{1}$ & $\epsilon_{2}$ & $\epsilon_{\mathrm{ex}, 2}$ & $\mathrm{~K}_{\mathrm{R}}$ & $\begin{array}{c}\tau_{1} \\
\text { (min) }\end{array}$ & $\begin{array}{c}\tau \\
(\min )\end{array}$ & $\underset{(\min )}{D}$ & $\begin{array}{c}\tau_{\mathrm{F}} \\
(\min )\end{array}$ & $\begin{array}{c}\tau_{\mathrm{M}} \\
(\mathrm{min})\end{array}$ & $\epsilon_{1} \Delta T_{1}$ & $\epsilon_{2} \Delta T_{2}$ & $b_{1}$ & $b_{2}$ \\
\hline first-ord & 0.77 & 0.46 & 0.70 & 2.5 & 0 & 10 & 1.6 & 1 & 0.1 & -442.8 & -34.5 & 0.15 & 0.15 \\
\hline wrong-way behavior (B) & 0.80 & 0.80 & 0.70 & 2 & 0.5 & 1 & 1 & 0.5 & 0.1 & -8.964 & -8.964 & 0.10 & 0.10 \\
\hline
\end{tabular}

${ }^{a} K_{F}=1$.

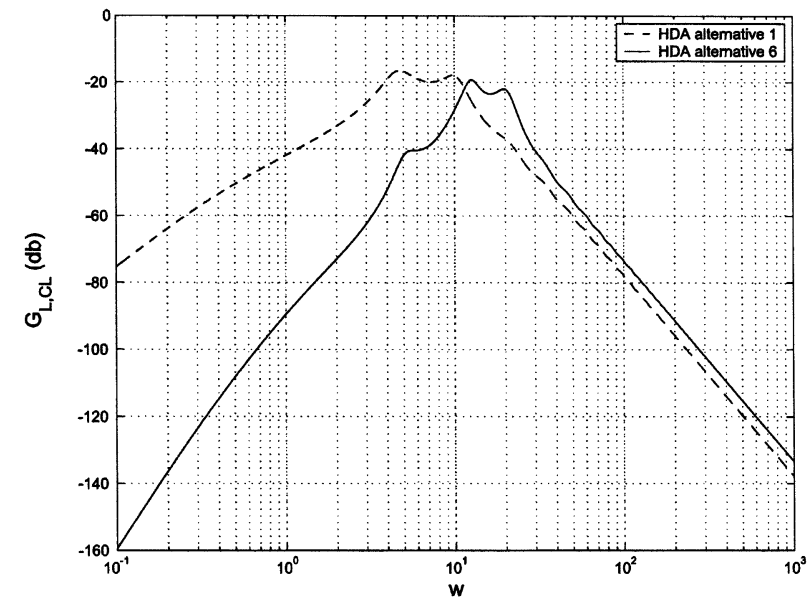

Figure 21. Closed-loop load-transfer functions for HDA design alternatives 1 and 6 .

Table 6. Controller Parameters for HDA Design Alternatives

\begin{tabular}{|c|c|c|c|c|c|c|c|c|}
\hline \multirow[b]{2}{*}{ alternative } & \multicolumn{2}{|c|}{$\begin{array}{c}\text { temperature } \\
\text { loop } 1\end{array}$} & \multicolumn{2}{|c|}{$\begin{array}{c}\text { temperature } \\
\text { loop } 2\end{array}$} & \multicolumn{2}{|c|}{$\begin{array}{c}\text { temperature } \\
\text { loop } 3\end{array}$} & \multicolumn{2}{|c|}{$\begin{array}{l}\text { temperature } \\
\text { loop } 4\end{array}$} \\
\hline & $\mathrm{K}_{\mathrm{C} 1}$ & $\tau_{11}$ & $\mathrm{~K}_{\mathrm{C} 2}$ & $\tau_{12}$ & $\mathrm{~K}_{\mathrm{C} 3}$ & $\tau_{13}$ & $\mathrm{~K}_{\mathrm{C} 4}$ & $\tau_{14}$ \\
\hline $\begin{array}{l}1 \\
6\end{array}$ & $\begin{array}{l}6.41 \\
6.41\end{array}$ & $\begin{array}{l}2.04 \\
2.53\end{array}$ & $\begin{array}{l}-0.0029 \\
-0.017\end{array}$ & $\begin{array}{l}0.72 \\
0.70\end{array}$ & $\begin{array}{c}- \\
-0.037\end{array}$ & $\overline{-}$ & $-\overline{0} .038$ & $\overline{0.49}$ \\
\hline
\end{tabular}

complex heat-integration scheme, alternative 6 . The peak in $\mathrm{T}_{\text {in }}$ is reduced by $79 \%$ from 0.96 to $0.2^{\circ} \mathrm{C}$ ) and the settling time (to reach $\pm 0.05^{\circ} \mathrm{C}$ of the set point) is also reduced by $0.9 \%$ compared to the responses of al ternative 1. However, little difference in the set-point response is observed (Figure 22B).

Again, time-domain and frequency-domain analyses confirm that better load responses can be achieved using the more complex heat-integration scheme.

At the design phase, alternative 6 gives a slightly better gain margin in design $(G M=0.47)$, and at the control phase, it gives better load rejection as a result of the increased number of temperature control loops (giving a steeper slope at low frequency and lower peak at high frequency).

\section{Conclusion}

In this work, a systematic approach is proposed to model complex FEHE schemes. A simple measure, the overall effectiveness, can be derived directly from the flowsheet. Given the reactor model, the controllability of a particular flowsheet can be evaluated on the basis of the gain margin (GM) of design. An interpretation based on the heat-generation and heat-removal curves is also given. With the controllability measure, implications for design are also explored. Because a loss of controllability comes from the positive feedback loop, several design parameters are studied, and design heuristics are proposed to give more controllable heatintegration schemes. Two examples, a simple two-FE HE example and an HDA example, are used to illustrate the assessment of controllability based on process
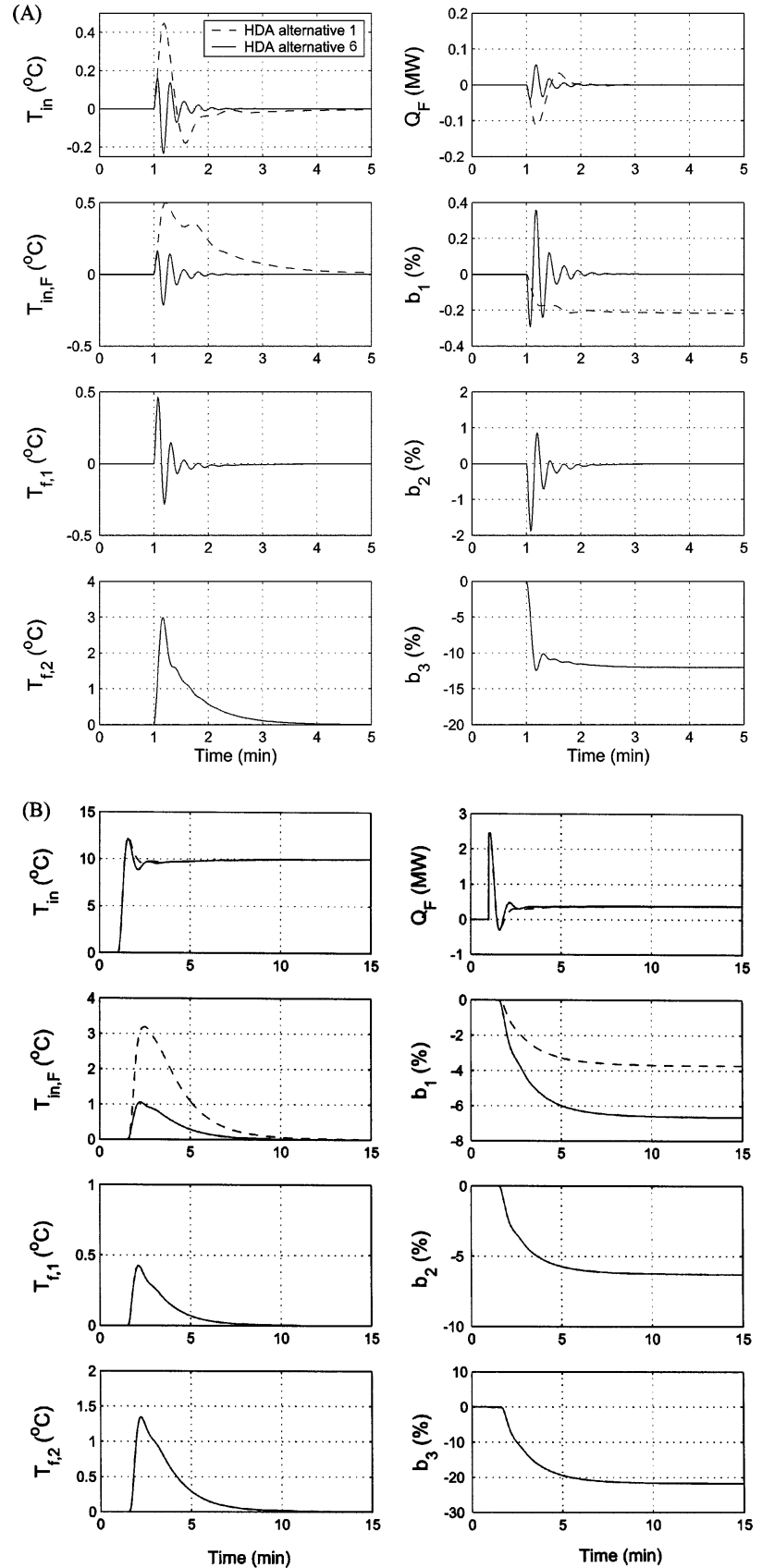

Figure 22. Closed-loop performances for alternatives 1 and 6 of the HDA process under: (A) $+10^{\circ} \mathrm{C}$ feed temperature change, (B) $+10^{\circ} \mathrm{C}$ set-point change in $\mathrm{T}_{\text {in }}$.

flowsheets. The results show that, contrary to expectations, some complex heat-integrated reactor design alternatives (e.g., alternatives 6 and 7 of the HDA example) are indeed more controllable than some of the simpler heat-integration schemes (e.g., alternative 1). For the control part, because of the availability of more manipulated inputs, e.g., the bypass ratio for the FEHEs, the system naturally leads to a multivariable control system. Contrary to one's intuition, multivari- 
able control of FEHE/reactor systems leads to a steeper slope and lower peak value in the load-transfer function, and this results in improved disturbance rejection.

\section{Acknowledgment}

Financial support provided by the National Science Council of Taiwan is gratefully acknowledged. We also thank Professor W. D. Seider for insightful comments.

\section{Appendix A}

To exchange sensible and latent heat between two streams, the design equation for a typical shell-and-tube exchanger becomes

$$
\begin{aligned}
Q & =\left(m C_{p}\right)_{H}\left(T_{1}-T_{2}\right)=\left(m C_{p}\right)_{C} \lambda \\
& =U A \frac{\left(T_{1}-T_{3}\right)-\left(T_{2}-T_{3}\right)}{\ln \frac{T_{1}-T_{3}}{T_{2}-T_{3}}}
\end{aligned}
$$

where $Q$ is the heat transferred; $T_{1}$ and $T_{2}$ are the hotstream inlet and outl et temperatures, respectively; $T_{3}$ is the cold-stream (steam-generator) temperature; $\left(\mathrm{mC}_{\mathrm{p}}\right)_{\mathrm{H}}$ is the hot-stream heat-capacity flow rate; $\left(\mathrm{mC}_{\mathrm{p}}\right)_{\mathrm{C}}$ is the cold-stream heat-capacity flow rate; UA is the overall heat-transfer coefficient into the heat-transfer area; and $\lambda$ is the latent heat of the cold stream.

Rearranging eqs $A 1$ and $A 2$, we have

$$
\ln \frac{T_{1}-T_{3}}{T_{2}-T_{3}}=\frac{U A}{\left(\mathrm{mC}_{\mathrm{p}}\right)_{\mathrm{H}}}
$$

Using the exponential operation for eq $\mathrm{A} 3$ gives

$$
\frac{T_{1}-T_{3}}{T_{2}-T_{3}}=\exp \left[\frac{U A}{\left(\mathrm{mC}_{\mathrm{p}}\right)_{H}}\right]
$$

Letting $B=\exp \left[U A /\left(m C_{p}\right)_{H}\right]$, we obtain

$$
\frac{\mathrm{T}_{1}-\mathrm{T}_{3}}{\mathrm{~T}_{2}-\mathrm{T}_{3}}=\mathrm{B}
$$

Rearranging eq $\mathrm{A} 5$ then gives

$$
\mathrm{T}_{2}=\mathrm{T}_{1}-\left(\frac{\mathrm{B}-1}{\mathrm{~B}}\right)\left(\mathrm{T}_{1}-\mathrm{T}_{3}\right)
$$
as

Now, define the modified effectiveness of a reboiler

$$
\begin{aligned}
\epsilon_{\mathrm{ex}} & =\frac{B-1}{B}=1-\frac{1}{B} \\
& =1-\frac{1}{\exp \left[\mathrm{UA} /\left(\mathrm{mC}_{\mathrm{p}}\right)_{\mathrm{H}}\right]}
\end{aligned}
$$

Then, eq $\mathrm{A} 6$ becomes

$$
\mathrm{T}_{2}=\mathrm{T}_{1}-\epsilon_{\mathrm{ex}}\left(\mathrm{T}_{1}-\mathrm{T}_{3}\right)
$$

Finally, we can find the relationship between the effectiveness of the reboiler and the steam temperature as

$$
\epsilon_{\mathrm{ex}}=\frac{\mathrm{T}_{1}-\mathrm{T}_{2}}{\mathrm{~T}_{1}-\mathrm{T}_{3}}
$$

\section{Appendix B}

From the definition of the effectiveness of a heat exchanger, we have

$$
\mathrm{T}_{\text {in }}=\left(1-\epsilon_{1}\right) \mathrm{T}_{\mathrm{f}}+\epsilon_{1} \mathrm{~T}_{\text {out }, 1}
$$

and

$$
\mathrm{T}_{\mathrm{e}}=\epsilon_{1} \mathrm{~T}_{\mathrm{f}}+\left(1-\epsilon_{1}\right) \mathrm{T}_{\text {out, }}
$$

From the definition of the effectiveness of a reboiler, we have

$$
\mathrm{T}_{\text {out }, 1}=\left(1-\epsilon_{\mathrm{ex}, 1}\right) \mathrm{T}_{\text {out }}+\epsilon_{\mathrm{ex}, 1} \mathrm{~T}_{\mathrm{s}, 1}
$$

Substituting eq B3 into eq B1 gives

$$
\mathrm{T}_{\text {in }}=\left(1-\epsilon_{1}\right) \mathrm{T}_{\mathrm{f}}+\epsilon_{1}\left(1-\epsilon_{\mathrm{ex}, 1}\right) \mathrm{T}_{\text {out }}+\epsilon_{1} \epsilon_{\mathrm{ex}, 1} \mathrm{~T}_{\mathrm{S}, 1}
$$

Here, the cold-stream temperature for the reboiler remains constant. Hence, we can cancel the term $\epsilon_{1} \epsilon_{\mathrm{ex}, 1} T_{\mathrm{s}, 1}$ from the RHS of eq B4. In addition, because we know that the reactor transfer function is $G_{R}$ (describing the dynamic response between $T_{\text {in }}$ and $T_{\text {out }}$ ), eq B4 becomes

$$
T_{\text {in }}=\left(1-\epsilon_{1}\right) T_{f}+\epsilon_{1}\left(1-\epsilon_{e x, 1}\right) G_{R} T_{\text {in }}
$$

Rearranging eq B5, we obtain

$$
\mathrm{T}_{\text {in }}=\frac{\left(1-\epsilon_{1}\right)}{1-\epsilon_{1}\left(1-\epsilon_{\mathrm{ex}, 1}\right) \mathrm{G}_{\mathrm{R}}} \mathrm{T}_{\mathrm{f}}
$$

From eq B2, we know the relationship between $T_{e}$ and $T_{\text {out,1. }}$. Substituting eq B3 into eq B2 gives

$$
\mathrm{T}_{\mathrm{e}}=\epsilon_{1} \mathrm{~T}_{\mathrm{f}}+\left(1-\epsilon_{1}\right)\left(1-\epsilon_{\mathrm{ex}, 1}\right) \mathrm{T}_{\text {out }}
$$

Here, the relationship between $T_{\text {in }}$ and $T_{\text {out }}$ is given by $\mathrm{G}_{\mathrm{R}}$. Again, we obtain

$$
\mathrm{T}_{\mathrm{e}}=\epsilon_{1} \mathrm{~T}_{\mathrm{f}}+\left(1-\epsilon_{1}\right)\left(1-\epsilon_{\mathrm{ex}, 1}\right) \mathrm{G}_{\mathrm{R}} \mathrm{T}_{\text {in }}
$$

From eq B6, we obtain the relationship between $T_{\text {in }}$ and $T_{f}$. Substituting eq B6 into eq B8 then gives

$$
\mathrm{T}_{\mathrm{e}}=\epsilon_{1} \mathrm{~T}_{\mathrm{f}}+\frac{\left(1-\epsilon_{1}\right)^{2}\left(1-\epsilon_{\mathrm{ex}, 1}\right) \mathrm{G}_{\mathrm{R}}}{1-\epsilon_{1}\left(1-\epsilon_{\mathrm{ex}, 1}\right) \mathrm{G}_{\mathrm{R}}} \mathrm{T}_{\mathrm{f}}
$$

Then

$$
\frac{\mathrm{T}_{\mathrm{e}}}{\mathrm{T}_{\mathrm{f}}}=\epsilon_{1}+\frac{\left(1-\epsilon_{1}\right)^{2}\left(1-\epsilon_{\mathrm{ex}, 1}\right) \mathrm{G}_{\mathrm{R}}}{1-\epsilon_{1}\left(1-\epsilon_{\mathrm{ex}, 1}\right) \mathrm{G}_{\mathrm{R}}}
$$

\section{Appendix C}

It is assumed that integral action (e.g., a PI controller) is employed in all three temperature loops. From the definition, the sensitivity function of the first loop $\left(Q_{F}-\right.$ $\left.T_{\text {in }}\right)$ is

$$
\mathrm{S}_{1}=\frac{1}{1+\mathrm{G}_{\mathrm{F}} \mathrm{K}_{1}}=\frac{1}{1+\frac{\mathrm{K}_{\mathrm{F}}}{\tau_{\mathrm{F}} \mathrm{S}+1} \mathrm{~K}_{\mathrm{Cl}}\left(\frac{\tau_{11} \mathrm{~S}+1}{\tau_{11} \mathrm{~S}}\right)}
$$

where $G_{F}$ is the process transfer function and $K_{1}$ is the controller transfer function. At low frequency, the integrator (1/s) in the denominator of the loop transfer function $\left(\mathrm{G}_{\mathrm{F}} \mathrm{K}_{1}\right)$ makes $\mathrm{G}_{\mathrm{F}} \mathrm{K}_{1}$ dominant. Taking the limit, we have 


$$
\lim _{s \rightarrow 0} S_{1}=\lim _{s \rightarrow 0} \frac{1}{1+G_{F} K_{1}}=\lim _{s \rightarrow 0} \frac{1}{G_{F} K_{1}}=\lim _{s \rightarrow 0} \frac{\tau_{11} s}{K_{F} K_{C 1}}=0
$$

From the block diagram, the closed-loop load-transfer function (from $T_{f}$ to $T_{\text {in }}$ ) becomes (Table 1 )

$$
\mathrm{G}_{\mathrm{L}, \mathrm{CS} 1}(\mathrm{~s})=\frac{\left(1-\epsilon_{1}\right)\left(1-\epsilon_{2}\right)}{1-\epsilon_{1} \epsilon_{2}\left(1-\epsilon_{\mathrm{ex}, 2}\right)} \frac{\mathrm{S}_{1}}{1-\epsilon_{\mathrm{o}}{ }^{(2)} \mathrm{S}_{1} \mathrm{G}_{\mathrm{R}}}
$$

Substituting eq C2 into eq $\mathrm{C} 3$ and taking the limit, one obtains

$$
\begin{aligned}
\lim _{\mathrm{s} \rightarrow 0} G_{L, C S 1}(s) & =\lim _{\mathrm{s} \rightarrow 0}\left[\frac{\left(1-\epsilon_{1}\right)\left(1-\epsilon_{2}\right)}{1-\epsilon_{1} \epsilon_{2}\left(1-\epsilon_{\mathrm{ex}, 2}\right)} \frac{\mathrm{S}_{1}}{1-\epsilon_{\mathrm{o}}^{(2)} \mathrm{S}_{1} \mathrm{G}_{\mathrm{R}}}\right] \\
& =\lim _{\mathrm{s} \rightarrow 0} \frac{\left(1-\epsilon_{1}\right)\left(1-\epsilon_{2}\right)}{\epsilon_{2}\left(1-\epsilon_{\mathrm{ex}, 2}\right)} \mathrm{S}_{1} \\
& =\lim _{\mathrm{s} \rightarrow 0} \frac{\left(1-\epsilon_{1}\right)\left(1-\epsilon_{2}\right)}{\epsilon_{1} \epsilon_{2}\left(1-\epsilon_{\mathrm{ex}, 2}\right)} \frac{\tau_{11} \mathrm{~S}}{\mathrm{~K}_{\mathrm{F}} \mathrm{K}_{\mathrm{C} 1}}
\end{aligned}
$$

Therefore, in the low-frequency range, the magnitude of the closed-loop load-transfer function can be expressed as

$$
\left|\mathrm{G}_{\mathrm{L}, \mathrm{CS} 1}(\mathrm{j} \omega)\right|=\frac{\left(1-\epsilon_{1}\right)\left(1-\epsilon_{2}\right)}{1-\epsilon_{1} \epsilon_{2}\left(1-\epsilon_{\mathrm{ex}, 2}\right)} \frac{\tau_{11}}{\mathrm{~K}_{\mathrm{F}} \mathrm{K}_{\mathrm{Cl}}} \omega
$$

Taking the logarithm and using decibel (db) as the unit, we have

$$
\begin{aligned}
& 20 \log \left|G_{L, C S 1}(j \omega)\right|= \\
& 20 \log \left[\frac{\left(1-\epsilon_{1}\right)\left(1-\epsilon_{2}\right)}{1-\epsilon_{1} \epsilon_{2}\left(1-\epsilon_{\mathrm{ex}, 2}\right)} \frac{\tau_{11}}{\mathrm{~K}_{\mathrm{F}} \mathrm{K}_{\mathrm{C} 1}}\right]+20 \log (\omega)
\end{aligned}
$$

This gives a straight line with a slope of $+20 \mathrm{db} /$ decade.

Similarly, the closed-loop load-transfer function for control structure CS2 (from $T_{f}$ to $T_{\text {in }}$ ) is also shown in Table 1. Taking the limit, we have

$$
\begin{aligned}
& \lim _{\mathrm{s} \rightarrow 0} G_{L, C S 2}(s)= \\
& \lim _{s \rightarrow 0} \frac{\left(1-\epsilon_{1}\right)\left(1-\epsilon_{2}\right) S_{1} S_{2} /\left(1-\epsilon_{1} S_{1} S_{2} G_{R}\right)}{1-S_{2}^{\prime} \epsilon_{2}\left(1-\epsilon_{\mathrm{ex}, 2}\right)\left[\epsilon_{1}+\frac{\left(1-\epsilon_{1}\right)^{2} S_{1} S_{2} G_{R}}{1-\epsilon_{1} S_{1} S_{2} G_{R}}\right]} \\
&=\lim _{s \rightarrow 0}\left(1-\epsilon_{1}\right)\left(1-\epsilon_{2}\right) S_{1} S_{2} \\
&\left.=\lim _{s \rightarrow 0}\left(1-\epsilon_{1}\right)\left(1-\epsilon_{2}\right) \frac{\tau_{11} \tau_{12} S^{2}}{K_{F} K_{C 1} K_{b 1} K_{C 2}} \quad \text { (C } 7\right)
\end{aligned}
$$

Again, taking the logarithm, we have

$$
\begin{aligned}
& 20 \log \left|\mathrm{G}_{\mathrm{L}, \mathrm{CS} 1}(\mathrm{j} \omega)\right|= \\
& 20 \log \left[\frac{\left(1-\epsilon_{1}\right)\left(1-\epsilon_{2}\right) \tau_{11} \tau_{12}}{\mathrm{~K}_{\mathrm{F}} \mathrm{K}_{\mathrm{C} 1} \mathrm{~K}_{\mathrm{b} 1} \mathrm{~K}_{\mathrm{C} 2}} \frac{\tau_{11}}{\mathrm{~K}_{\mathrm{F}} \mathrm{K}_{\mathrm{C} 1}}\right]+40 \log (\omega)
\end{aligned}
$$

This is a straight line with a slope of $+40 \mathrm{db} /$ decade. A similar result can be derived for the CS3 structure

$$
\begin{aligned}
& \lim _{\mathrm{s} \rightarrow 0} G_{L, C S 3}(s)= \\
& \lim _{s \rightarrow 0}\left(1-\epsilon_{1}\right)\left(1-\epsilon_{2}\right) S_{1} S_{2} S_{3} /\left(1-\epsilon_{1} S_{1} S_{2} G_{R}\right) \\
& 1-S_{2} S_{3} \epsilon_{2}\left(1-\epsilon_{e x, 2}\right)\left[\epsilon_{1}+\frac{\left(1-\epsilon_{1}\right)^{2} S_{1} S_{2} G_{R}}{1-\epsilon_{1} S_{1} S_{2} G_{R}}\right]=\lim _{S \rightarrow 0}\left(1-\epsilon_{1}\right)\left(1-\epsilon_{2}\right) S_{1} S_{2} S_{3} \\
&= \lim _{s \rightarrow 0}\left(1-\epsilon_{1}\right)\left(1-\epsilon_{2}\right) \times \\
& \frac{\tau_{11} S}{K_{F} K_{C 1}} \frac{\tau_{12} S}{K_{b 1} K_{C 2}} \frac{\tau_{13} S}{K_{b 2} K_{C 3}} \text { (C9) }
\end{aligned}
$$

Equation $\mathrm{C} 9$ reveals that the magnitude plot at low frequency is a straight line with a slope of $+60 \mathrm{db} /$ decade.

\section{Literature Cited}

(1) Bildea, C. S.; Dimian, A. C. Stability and Multiplicity Approach to the Design of Heat-Integrated PFR. AIChE J . 1998, 44, 2703.

(2) Chen, Y. H.; Yu, C. C. Interaction between Thermal Efficiency and Dynamic Controllability for Heat-I ntegrated Reactors. Comput. Chem. Eng. 2000, 24, 1077.

(3) Douglas, J . M.; Orcutt, J . C.; Berthiaume, P. W. Design and Control of F eed-Effluent Exchanger-Reactor Systems. Ind. Eng. Chem. Fundam. 1962, 1, 253.

(4) Kays, W. M.; London, A. L. Compact Heat Exchangers; McGraw-Hill: New York, 1984.

(5) Luyben, W. L. Simple Method for Tuning SISO Controllers in Multivariable Systems. Ind. Eng. Chem. Process Des. Dev. 1986, 25, 654.

(6) Luyben, W. L. External versus Internal Open-Loop Unstable Processes. Ind. Eng. Chem. Res. 1998, 37, 2713.

(7) Luyben, W. L. Effect of Kinetic, Design, and Operating Parameters on Reactor Gain. Ind. Eng. Chem. Res. 2000, 39, 2384.

(8) Luyben, W. L.; Luyben, M. L. Essentials of Process Control; McGraw-Hill: New York, 1997.

(9) Luyben, W. L.; Tyreus, B. D.; Luyben, W. L. Plantwide Process Control; McGraw-Hill: New York, 1999.

(10) Morud, J. C.; Skogestad, S. Dynamic Behavior of Integrated Plants. J . Process Control 1996, 6, 145.

(11) Polley, G. T.; Heggs, P. J . Don't Let the Pinch Pinch You. Chem. Eng. Prog. 1999, 95 (12), 27.

(12) Shen, S. H.; Yu, C. C. Use of Relay-Feedback Test for Automatic Tuning of Multivariable Systems. AI ChE J . 1994, 40, 627.

(13) Seider, W. D.; Seader, J . D.; Lewin, D. R. Process Design Principles: Synthesis, Analysis, and Evaluation; J ohn Wiley: New York, 1999.

(14) Silverstein, J. L.; Shinnar, R. Effect of Design on the Stability and Control of Fixed Bed Catalytic Reactors with Heat Feedback. 1. Concept. Ind. Eng. Chem. Process Des. Dev. 1982 21, 241.

(15) Terrill, D. L.; Douglas, J . M. A T-H Method for HeatExchanger Network Synthesis. Ind. Eng. Chem. Res. 1987, 26, 175.

(16) Terrill, D. L.; Douglas, J. M. Heat-Exchanger Network Analysis. 1. Optimization. Ind. Eng. Chem. Res. 1987, 26, 685.

(17) Terrill, D. L.; Douglas, J. M. Heat-Exchanger Network Analysis. 2. Steady-State Operability Evaluation. Ind. Eng. Chem. Res. 1987, 26, 691.

(18) Tyreus, B. D.; Luyben, W. L. Unusual Dynamics of a Reactor/Preheater Process with Deadtime, Inverse Response and Open-Loop I nstability. J . Process Control 1993, 3, 241.

(19) Yan, Q. Z.; Yang, Y. H.; Huang, Y. L. Cost-Effective Bypass Design of Highly Controllable Heat-Exchanger Networks. AIChE J. 2001, 47, 2253.

Received for review April 30, 2002 Revised manuscript received December 3, 2002 Accepted March 19, 2003 